\title{
Nol12 is a multifunctional endonuclease at the nexus of RNA and DNA metabolism
}

Scott, D. D. ${ }^{1,2, \dagger}$, Trahan, C. ${ }^{1,3, \dagger}$, Zindy, P.J. ${ }^{1, \dagger}$, Aguilar, L. C. ${ }^{1}$, Delubac, M. Y. ${ }^{1,3}$, Wei, K. E. ${ }^{1,4}$, Oeffinger, M. ${ }^{1,2,3, *}$

${ }^{1}$ Institut de Recherches Cliniques de Montréal, 110 Avenue des Pins Ouest, Montréal, Québec, Canada, H2W 1R7; ${ }^{2}$ Faculty of Medicine, Division of Experimental Medicine, McGill University, Montréal, Québec, Canada H3A 1A3; ${ }^{3}$ Département de Biochimie, Faculté de Médecine, Université de Montréal, Montréal, Québec, Canada H3T 1J4;

${ }^{*}$ To whom correspondence should be addressed: Tel: +1 514987 5668; Email: marlene.oeffinger@ircm.qc.ca;

${ }^{\dagger}$ The authors wish it to be known that, in their opinion, the first three authors should be regarded as joint First Authors.

${ }^{4}$ Current Address: Human Oncology and Pathogenesis Program, Memorial Sloan Kettering Cancer Center, New York, New York. 


\begin{abstract}
Endo- and exonucleases are major contributors to RNA metabolism through their diverse roles in maturation and turnover of different species of RNA as well as transcription. Recent data suggests RNA nucleases also affect genome stability programs and act along DNA repair pathways. Here, we describe Nol12 as a multifunctional RNA/DNA endonuclease found in different subcellular compartments - the nucleoplasm, where it co-localizes with the RNA/DNA helicase Dhx9 and paraspeckles, nucleoli as well as GW/P-bodies. We show that Nol12 is required for a key step in ribosomal RNA processing, separating large and small subunit precursors at site 2, rerouting ribosome biogenesis via an alternative pathway in its absence to ensure ribosome production. Furthermore, loss of Nol12 results in increased oxidized DNA levels followed by a rapid p53-independent ATR-Chk1-mediated apoptotic response, suggesting a role for Nol12 in the prevention or resolution of oxidative DNA damage. Identification of a complex Nol12 interactome, which includes NONO, Dhx9 and DNA-PK, further supports its diverse functions in RNA metabolism and DNA maintenance, establishing Nol12 as a multifunctional endonuclease.
\end{abstract}




\section{INTRODUCTION}

Cells contain many different species of RNA, all of which undergo extensive processing to either achieve their mature functional form, or to be degraded as part of quality control or turnover mechanisms $(1,2)$. Endo- and exonucleases are the essential players along all of these pathways, and, in most cases, they act in concert on specific RNA substrates. However, many nucleases have multiple functions and are not just acting on one single pathway or species of RNA, but are rather involved in the processing and/or turnover of different types of RNAs along different pathways. Such multifunctionality has been demonstrated for several endo and exonucleases in higher eukaryotes. For example, the nuclear 5'-3' exonuclease Xrn2 has a wide range of conserved cellular functions on a variety of RNA species including processing of pre-rRNA, nuclear RNA quality control, transcription termination, snoRNA maturation and miRNA turnover (3). A number of components of the multi-nuclease exosome complex were also shown to function on diverse RNA substrates within different cellular subcompartments, with hRrp6/PM/Scl-100 fulfilling several roles in nuclear RNA metabolism, including nucleolar pre-rRNA processing and nuclear mRNA surveillance $(4,5)$, while hDis3 was found to act in surveillance as well as degradation of aberrant pre-mRNAs and pre-snoRNAs $(6,7)$ and has also been implicated in paraspeckles formation (6). Besides exonucleases, recent studies have also highlighted the roles of endonucleases in RNA metabolism in higher eukaryotes, and several were shown to contribute to RNA turnover in various subcellular compartments (8). Amongst them hDis3, which contains dual exo-endonuclease activity, degrading both aberrant rRNA processing precursor and cryptic unstable transcripts (CUTs) via its endonuclease activity in the nucleus, while its variant, hDis3L, functions exonucleolytically in the cytoplasm (9-11). Another endonuclease, Rnt1/RNasellI, was reported to process both pre-rRNAs and snoRNAs, whereas multiple endonucleases, Dicer, Ago2 and C3PO, are involved in the maturation of small interfering RNAs; in addition, Dicer also processes pre-micro RNAs into their mature forms (8).

Besides their numerous and often diverse roles in RNA metabolism, mounting evidence over the last few years supports the idea that RNA-binding and processing proteins are not only involved in different steps of RNA life but can also affect genome stability programs and even function directly in DNA repair. A number of large-scale genetic and proteomic studies of proteins involved in DNA DDR showed enrichment for RNA processing proteins, suggesting that RNA metabolism and DNA repair 
pathways intersect functionally (12). Along such lines, requirement for Rrp6 in the repair of DNA doublestrand breaks (DSBs) has recently been demonstrated in HeLa cells (13), and Xrn2 was show to cooperate with the helicase senataxin to resolve RNA:DNA hybrids (14). A function for the endonuclease Dicer in DNA damage and repair has also been shown $(15,16)$. Moreover, known RNA-protein structures within the nucleus, such as paraspeckles and the nucleolus, and some of their components have been implicated in DNA damage response $(\mathrm{DDR})(17,18)$. While the exact roles played by these nucleases in the cell's response to different sources of DNA damage is still mostly unexplored, different mechanisms for such cross-functionality have been proposed (19). Involvement on the level of mRNA regulation, direct participation in the DDR, or prevention of DNA damage are all suggested modes of function of how RNA processing proteins could impact the maintenance of genome integrity.

In this manuscript we describe the role of the human protein Nol12 in both RNA and DNA metabolism. Previously, the Drosophila Nol12-homologue Viriato was shown to modulate signaling during eye development, and its interactor genes were overwhelmingly involved in development of the nervous system (20). Loss of Viriato resulted in cell proliferation, developmental delay and apoptosis. Moreover, Viriato as well as the mouse Nol12-homologue Nop25 were shown to affect nucleolar integrity $(20,21)$, while its yeast homologue, Rrp17, was identified as a putative 5'-3' exonuclease with function in ribosome biogenesis (22); a potential role for Nol12 in ribosome maturation has also been suggested (4). However, public human proteome data sets analyzing protein profiles showed localization of human Nol12 not only within the nucleolus but also the nucleo- and cytoplasm (23), suggesting functions for Nol12 outside of the nucleolus and ribosome maturation. In line with this, Nol12 was previously identified to interact with p33Monox, a human neuron-expressed cytosolic protein and inhibitor of amyloid beta precursors protein (APP) and Bcl2 phosphorylation from a human brain cDNA library (24).

Here, we show Nol12 to be a multifunctional nuclease exhibiting endonucleolytic activity in vitro on RNA and DNA substrates. The identification of a diverse Nol12 interactome, supported by immunofluorescence microscopy, suggests a role for the nuclease in RNA metabolism in different subcellular compartments such as nucleoli, the paraspeckles, and P-bodies. Nol12 is required for a keyprocessing step in ribosomal RNA processing, separating small and large subunit rRNAs. In addition, we 
show that Nol12 has a role in management of oxidized DNA that is linked to a rapid pro-apoptotic ATRmediated DNA damage response in its absence. Moreover, Nol12 associates and co-localizes with the DNA/RNA DEAD-box helicase Dhx9 as well as paraspeckle components NONO and SfpQ, further indicating a role for Nol12 in genome instability prevention. Together with our identification of a complex Nol12-interactome, these data suggest a function for the protein along various RNA metabolism pathways and DNA maintenance processes, providing insights into the diverse roles of an endonuclease at the intersection between RNA - DNA life and surveillance.

\section{MATERIALS AND METHODS}

\section{DNA constructs}

For recombinant Nol12 (rNol12) expression, the cDNA of NOL12 was amplified by PCR from pRS4143xHA-NOL12 (22) with oligonucleotides Ndel-NOL12-F (5'-ccccatatgggccgcaacaagaagaagaa-3') and Xhol-NOL12-R (5'-gggctcgagcgggecctgaaacagcacttccaggccgctgctctccccgctgtgccgtgc-3'). The PCR product was cloned into Ndel-Xhol sites of pET21a to generate plasmid pET21a-NOL12-6xHis. In order to construct a PrA-NOL12 encoding plasmid for Flip-in recombination Flp-In T-REx system (see cell culture section), the ORF of NOL12 was amplified by PCR from the same template as above with oligonucleotides Ncol-NOL12-F (5'-ggaatcaggaccatgggaaccggccgcaacaagaagaagaagcgagatggtga-3') and Notl-NOL12-R (5'-ggaatcaggagcggccgcctccccgctgtgccgtgcttgcctgtgagacggcggcgct-3'). The amplicon was cloned into Ncol-Notl sites of pENTR4 to generate pENTR4-NOL12. Protein A was amplified by PCR from pBXA (25) with oligonucleotides HindllI-PrA-F (5'-gctagcaagcttgaattcatggttggtactttctatcg-3') and HindIII-PrA-R (5'-cctgataagcttgaattcaggatcgtctttaaggcttt-3') and swapped with GFP into HindIII site of pFRT-TO-DEST-GFP to generate pFRT-TO-DEST-PrA. pENTR4-NOL12 and pFRT-TO-DEST-PrA were recombined with LR clonase to generate pFRT-TO-PrA-NOL12 according to the Gateway system instructions (Life Technologies). The same way, pFRT-TO-Flag-HA-NOL12 was generated by recombining pENTR4-NOL12 and pFRT-TO-DEST-Flag-HA, and pFRT-TO-PrA by recombining pENTR4 with pFRT-TO-DEST-PrA. 


\section{Recombinant protein expression and purification}

BL21 (DE3) pLysS cells transformed with pET21a-NOL12-6xHis were grown at $37^{\circ} \mathrm{C}$ up to $\mathrm{OD}_{600}=0.6$. Cells were induced with IPTG $(0.5 \mathrm{mM})$ for $1 \mathrm{~h}$ and harvested by centrifugation. The pellet was flash frozen in liquid $\mathrm{N}_{2}$ and stored at $-80^{\circ} \mathrm{C}$. The frozen pellet was thawed and lysed by vortexing in seven pellet volumes of (50mM Tris $\mathrm{pH} 8,150 \mathrm{mM} \mathrm{NaCl}, 10 \mathrm{mM}$ imidazole, $8 \mathrm{M}$ urea) until homogenous. The lysate was further homogenized using a Polytron homogenizer (Kinematica PT 1200 E) equipped with a $7 \mathrm{~mm}$ probe at $3 / 4$ maximum speed. The lysate was passed $10 \mathrm{x}$ through a $18 \mathrm{G} 1 / 2$ needle connected to a syringe. The cell lysate was cleared by centrifugation at $16,000 \mathrm{~g}$ for $20^{\prime}$ at $4^{\circ} \mathrm{C}$ and filtered with a 0.45 $\mu \mathrm{m}$ syringe filter. The cleared lysate was loaded in a $50 \mathrm{~mL}$ superloop connected to an AKTA purifier 10 FPLC system (GE Healthcare) and loaded on a $1 \mathrm{~mL}$ His-Trap HP column at a flow rate of $1 \mathrm{~mL} / \mathrm{min}$. The columns were washed with $10 \mathrm{~mL}$ of lysis/binding buffer, and the resin-bound $\mathrm{rNol}^{12-H i s_{6}}$ was refolded using a $20 \mathrm{~mL}$ gradient to $100 \%$ (50 mM Tris $\mathrm{pH} \mathrm{8,150} \mathrm{mM} \mathrm{NaCl,} 10 \mathrm{mM}$ imidazole). rNol12-His 6 was eluted with $5 \mathrm{~mL}$ of ( $50 \mathrm{mM}$ Tris $\mathrm{pH} 8,150 \mathrm{mM} \mathrm{NaCl}, 350 \mathrm{mM}$ imidazole). Imidazole was removed with a Hiprep 26/10 column equilibrated in $(20 \mathrm{mM}$ Tris $\mathrm{pH} 7.6,150 \mathrm{mM} \mathrm{NaCl}, 5 \mathrm{mM} \mathrm{MgCl}$ ) at a flow rate of 5 $\mathrm{mL} / \mathrm{min}$. The sample was concentrated with an Amicon Ultra-15 (3000 NMWL), protein concentration was measured using the Bradford method, and the samples were analyzed by SDS-PAGE.

\section{Radiolabeled RNA and DNA}

Radiolabeled RNA corresponding to T7 polymerase transcribed pBlueScript KS+ linearized by Xbal was used in the nuclease assay below. Briefly, $1.5 \mu \mathrm{g}$ of linearized and purified template was transcribed in 20 $\mu$ l of (40 mM Tris pH 7.9, $7.5 \mathrm{mM} \mathrm{MgCl}, 10 \mathrm{mM}$ DTT, $10 \mathrm{mM} \mathrm{NaCl}, 2 \mathrm{mM}$ spermidine, $0.5 \mathrm{mM}$ ATP, 0.5 mM CTP, 5 mM GTP, 0.06 mM UTP, 20 U RNasin (Promega), $20 \mu \mathrm{Ci}$ of [aP ${ }^{32}$ ]UTP (3000 Ci/mmol; Perkin-Elmer)). Reactions were stopped by adding one-tenth volume of $0.5 \mathrm{M} \mathrm{EDTA} \mathrm{pH} \mathrm{8.} \mathrm{Full} \mathrm{length}$ RNAs (35 nt) were purified on $12 \%$ denaturing acrylamide gels and eluted in $400 \mu \mathrm{L}$ of $\left(0.5 \mathrm{M} \mathrm{NH}_{4} \mathrm{OAc}\right.$, $10 \mathrm{mM} \mathrm{Mg}(\mathrm{OAc})_{2}, 1 \mathrm{mM}$ EDTA, $\left.0.1 \% \mathrm{SDS}\right)$ overnight. Eluted RNA were further extracted with phenol:chloroform (25:1) and precipitated with ethanol (ice-cold, $100 \%$ ). RNA pellets were resuspended in $40 \mu \mathrm{L} \mathrm{H} \mathrm{H}_{2} \mathrm{O}$ and counted with a beta counter. For the nuclease assays on ssDNA templates, an oligonucleotide corresponding to transcribed RNA above (5'-gggcgaattggagctccaccgcggtggcggccgct-3') 
was labeled with $\left[\mathrm{YP}^{32}\right.$ ]ATP $(3000 \mathrm{Ci} / \mathrm{mmol}$; Perkin-Elmer). For labeled dsDNA, a reverse complementary oligonucleotide was hybridized to the labeled oligonucleotide above. The dsDNA was then purified on denaturing acrylamide gels and eluted as described above.

The circular dsDNA template for the endonuclease assay was prepared as follows. An unrelated 572 bp fragment was amplified and radiolabeled with $\left[\alpha \mathrm{P}^{32}\right] \mathrm{dCTP}(3000 \mathrm{Ci} / \mathrm{mmol}$; Perkin-Elmer) by PCR. The free nucleotides and oligonucleotides were eliminated with a PCR cleanup column (Qiagen) and the labeled amplicon eluted in $49 \mu \mathrm{l}$. The cleaned up labeled DNA was phosphorylated in $55 \mu$ l with $10 \mathrm{U}$ of T4 PNK in 1X T4 DNA ligase buffer at $37^{\circ} \mathrm{C}$ for 30 minutes, and subsequently self-ligated in $300 \mu \mathrm{l}$ of $1 \mathrm{X}$ T4 DNA ligase buffer with $6000 \mathrm{U}$ of T4 DNA ligase at $16^{\circ} \mathrm{C}$ for 16 hours. The labeled DNA mixture was separated on a $4 \%$ denaturing acrylamide gel, and the circular dsDNA band was excised and eluted, precipitated and quantified as described above.

Circular RNA was prepared from pBS-U17 (26) digested with EcoRI and translated with T7 RNA

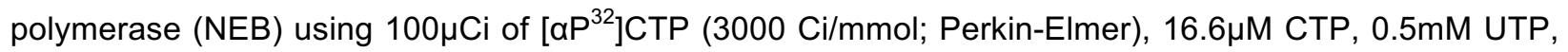
0.5mM ATP, $0.15 \mathrm{mM}$ GTP and 0.75mM GMP. Full length RNA was gel purified and circularized by gapsplint ligation with the following oligonucleotide; ggagacaaaccatgcaggaaacagttttcgaattgggtaccgggecccccc-3' (27, 28). Equal molar amount of RNA and oligonucleotide ( $1 \mathrm{pmol}$ of each in a volume of $100 \mu \mathrm{l})$ were denatured for 1 minute at $90^{\circ} \mathrm{C}$ and cooled to $22^{\circ} \mathrm{C}$ over a period of 15 minutes. T4 RNA ligase buffer was added to $1 \mathrm{x}$, DMSO to $10 \%$, ATP to $1 \mathrm{mM}$, RNasine (promega) to $1 \mathrm{U} / \mu \mathrm{l}$ and T4 RNA ligase to $1 \mathrm{U} / \mu \mathrm{l}$ in a final volume of $175 \mu \mathrm{l}$. The mixture was cooled from $22^{\circ} \mathrm{C}$ to $16^{\circ} \mathrm{C}$ over a period of 3 hours, and incubated at $16^{\circ} \mathrm{C}$ for 16 hours. The circular RNA was then gel purified as described above.

\section{Filter binding assay}

RNPs were reconstituted for 30 minutes at room temperature using $0.2 \mu \mathrm{M}$ rNol12-His, $0.3 \mu \mathrm{M}$ BSA and 10nM Cy5.5-RNA (5'-Cy5.5gagcucuuccgcagu-3') in $20 \mu \mathrm{l}$ of $20 \mathrm{mM}$ Tris $\mathrm{pH} 7.6,50 \mathrm{mM} \mathrm{KCl}$ without $\mathrm{MgCl}_{2}$. A negative control was performed in the absence of rNol12-His, and a 5-fold excess of tRNA (50nM) compared to the Cy5.5-RNA was used as a non-specific competitor for rNol12-His binding. During the 
incubation time, a nitrocellulose membrane was pre-equilibrated in the same buffer for 20 minutes, and placed in a Bio-Dot apparatus (BioRad). The samples were then filtered through the nitrocellulose membrane, and retained samples on the membrane were washed with 40 ul reconstitution buffer. The retained RNA on membrane was then resolved on a Li-Cor Odyssey Infrared scanner. The membrane was then blocked in $5 \%$ milk and blotted with an anti-His antibody (ABM; G020) to quantify the amount of Nol12 retained on the membrane. RNA corresponding to 1 ul of each reconstitution input were spotted on a nylon membrane as a loading control and scanned using a Li-Cor Odyssey. Signals for retained RNAs were normalized on the signal observed for the BSA only control. The difference in the amount of rNol12His retained on the membrane was then taken into account to adjust the normalized values for samples with and without tRNA.

\section{Nuclease assays}

Nuclease assay reactions were carried out in $20 \mu \mathrm{l}$ total volume of $(20 \mathrm{mM}$ Tris $\mathrm{pH} 7.6,150 \mathrm{mM} \mathrm{NaCl}, 5$ $\mathrm{mM} \mathrm{MgCl} 2)$. The concentration of $\mathrm{rNOL} 12$ either varied $(0,0.1,0.375,0.75$ and $1.5 \mu \mathrm{M})$ in reactions incubated at $30^{\circ} \mathrm{C}$ for 30 minutes, or $1.5 \mu \mathrm{M}$ was used for different times $\left(0^{\prime}, 2^{\prime}, 10^{\prime}, 30^{\prime}\right)$ at $30^{\circ} \mathrm{C}$. In the divalent cation assay, $5 \mathrm{mM} \mathrm{MnCl} 2$ or $50 \mathrm{mM}$ EDTA were also used instead of $\mathrm{MgCl}_{2}$. In all cases, $10 \mathrm{nM}$ of internally radiolabeled RNA, labeled deoxyoligonucleotides or Cy5.5-labeled RNAs were used for the assays. In the case of circular labeled dsDNA, $0.1 \mu \mathrm{M}$ of DNA was used in the assay. At the end of each reaction, $1 \mu \mathrm{l}$ of each reaction mixture was added to $9 \mu \mathrm{l}$ of RNA loading dye (95\% formamide, $0.025 \%$ bromophenol blue, $0.025 \%$ xylene cyanol, $0.025 \%$ SDS, $0.5 \mathrm{mM}$ EDTA). Samples were separated on a $12 \%$ denaturing poly-acrylamide gel at $250 \mathrm{~V}$ at room temperature and directly exposed using a phosphor screen overnight. The phosphor screen was developed on a Storm 860 Imager.

\section{Cell Culture and Drug Treatment}

HCT116 WT, HCT116 p53 ${ }^{-/}$, HEK293T and IMR-90 cells were grown in Dulbecco's Modified Eagle Medium (DMEM) supplemented with 10 \% Foetal Calf Serum (FCS) and Penicillin/Streptomycin (1000 IU, $1 \mathrm{mg} / \mathrm{mL}$ respectively; Wisent) at $37{ }^{\circ} \mathrm{C}$ with $5 \% \mathrm{CO}_{2}$. 
To create the PrA-NOL12 Flp-in cell line, pFRT-TO-PrA-NOL12 and pOG44 expressing the Flp recombinase were co-transfected in HEK293T FIp-In ${ }^{\mathrm{TM}}$ cells containing a single FRT recombination site according to the Flp-In ${ }^{\mathrm{TM}}$ T-REx ${ }^{\mathrm{TM}}$ core kit manufacturer's instructions (Life Technologies). Successful transformants were identified by a combination of hygromycin resistance and zeocin sensitivity and doxycycline-inducible expression of PrA- or PrA-Nol12 was verified by western blotting. PrA and PrANol12 expression was induced in the relevant cell lines with $1 \mu \mathrm{g} / \mathrm{mL}$ doxycycline for $24 \mathrm{~h}$ and monitored by western blotting using anti-PrA antibodies.

Synthetic siRNAs against NOL12, XRN2, p21, p27 and p53 and a scrambled (SCR) control were supplied by Sigma-Aldrich. siRNAs were transfected using Lipofectamine RNAiMAX (Life Technologies) in a reverse transfection protocol according to the manufacturer's instructions. Between $7.5 \times 10^{4}$ and $5.4 \times 10^{5}$ cells $/ \mathrm{mL}$ were transfected, depending on the duration of knockdown. Successful silencing of siRNA targets was monitored by western blotting. All siRNA sequences are listed in Supplementary Table 7.

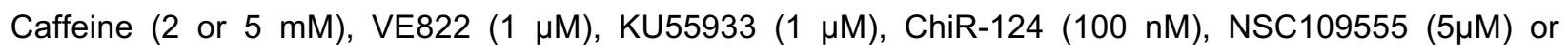
NU7441 $(0.5 \mu \mathrm{M})$ were added to the above growth media for the duration of the time course; these supplemented media were changed every $24 \mathrm{~h}$ throughout the time course to maintain an effective dose. Actinomycin $D(0.05 \mu \mathrm{g} / \mathrm{mL}$ or $1 \mu \mathrm{g} / \mathrm{mL})$ was applied to cells for $3 \mathrm{~h}$ immediately prior to downstream processing.

\section{Western Blotting}

siRNA-transfected cells were harvested at the indicated time points by trypsin-treatment, washed with PBS and lysed by sonication ( $5 \mathrm{~min} 30^{\prime \prime}$ on/off, $4^{\circ} \mathrm{C}$ ) in RIPA buffer $(50 \mathrm{mM}$ Tris, $150 \mathrm{mM} \mathrm{NaCl}, 0.1 \%$ SDS, $0.5 \%$ sodium deoxycholate, $1 \%$ Nonidet $\mathrm{P}-40, \mathrm{pH} 7.5)$ supplemented with cOmplete protease inhibitor, EDTA-free (Roche). Soluble fractions were resolved on a $4-12 \%$ gradient Bis-Tris NuPAGE ${ }^{\circledR}$ gel according to the manufacturer's instructions, transferred to a PVDF membrane which was blocked with 5 $\%$ milk or BSA in TBS+T (50 mM Tris, $150 \mathrm{mM} \mathrm{NaCl}, 0.05 \%$ Tween-20, $\mathrm{pH} 7.6)$ and probed with the indicated primary and secondary antibodies according to Supplementary Table 6. Secondary antibodyconjugated fluorescence was detected using the Li-Cor Odyssey Infrared scanner. 


\section{SSAP-MS/MS analysis of Nol12-containing complexes}

HEK293T FIp-In T-REx PrA-Nol12 cells were grown to $\sim 50 \%$ confluency, induced for $24 \mathrm{~h}$ with $1 \mu \mathrm{g} / \mathrm{mL}$ doxycycline and PrA-Nol12-containing complexes were lysed by cryogrinding (29). PrA-Nol12-containing mRNPs and those from negative controls (PrA-containing or non-epitope tagged) purifications were performed in duplicate with five volumes of extraction buffer $(20 \mathrm{mM} H E P E S-K O H ~ p H$ 7.4, $0.5 \%$ Triton, $1 \mathrm{x}$ mini complete EDTA-free protease inhibitor cocktail, 1:5000 antifoam A) supplemented with $100 \mathrm{mM} \mathrm{NaCl}(+/-100 \mu \mathrm{g} / \mathrm{mL}$ RNAse A) or $300 \mathrm{mM} \mathrm{NaCl}(+100 \mu \mathrm{g} / \mathrm{mL}$ RNAse A) as previously described (29). Briefly, $0.2 \mathrm{~g}$ of cryo-lysed cell powder was slightly thawed (1 minute on ice) and vortex mixed in extraction buffer. The samples were then sonicated ( $20 \mathrm{~W}, 2$ minutes, on ice). RNAse-treated samples were incubated for $10 \mathrm{~min}$ at room temperature. All samples were then centrifuged $\left(10\right.$ minutes, $\left.4{ }^{\circ} \mathrm{C}, 16000 \times \mathrm{g}\right)$ and the supernatant was then incubated (30 minutes, slow rotation, $4^{\circ} \mathrm{C}$ ) with $7.5 \mathrm{mg}$ of Dynabeads conjugated with rabbit $\operatorname{lgG}(160 \mu \mathrm{g} \operatorname{lgG} / \mathrm{mg}$ beads) previously washed with extraction buffer. Prior to on-bead digestion, the beads were washed ten times with extraction buffer; once with $100 \mathrm{mM} \mathrm{NH}{ }_{4} \mathrm{OAC} / 0.1 \mathrm{mM} \mathrm{MgCl} / 0.5 \%$ tritonX-100 (RT, slow rotation, 5 minutes); four times with $100 \mathrm{mM} \mathrm{NH}{ }_{4} \mathrm{OAC} / 0.1 \mathrm{mM} \mathrm{MgCl}_{2}$ (three times fast and once at $\mathrm{RT}$, slow rotation, 5 minutes); and once with $20 \mathrm{mM}$ Tris- $\mathrm{HCl}$ pH8.0. Subsequent to ssAP purification, one tenth of each affinity purification sample was eluted with $0.5 \mathrm{M} \mathrm{NH}_{4} \mathrm{OH}$ and resolved on $4-12 \%$ gradient Bis-Tris NuPAGE ${ }^{\circledR}$ gels for silver staining. The remaining samples were on-bead trypsin digested in a volume of $50 \mu \mathrm{l}\left(20 \mu \mathrm{g} / \mathrm{mL}\right.$ trypsin in $20 \mathrm{mM}$ Tris- $\mathrm{HCl} \mathrm{pH} 8.0,37^{\circ} \mathrm{C}, 900 \mathrm{rpm}, 16-20 \mathrm{~h}$; stopped with $2 \%$ formic acid; (30)) and analyzed by tandem mass spectrometry as described previously (31).

Nol12-interacting proteins were identified as follows. The highest total spectrum count values of the controls (Untagged, PrA; Supplementary Table 1) were subtracted from that of the PrA-Nol12 ssAP samples under the respective condition. A peptide was considered enriched in a PrA-Nol12 ssAP sample $(100 / 300 \mathrm{mM} \mathrm{NaCl}+/-$ RNAse A) if the spectrum count value for each replicate was $\geq 2$-fold greater than the highest spectrum count value recorded among the relevant controls (PrA and untagged) under the same purification conditions. The total number of unique peptide spectra recorded for each prey was then determined; preys were defined as Nol12- associated proteins if at least three enriched peptides were 
identified in both experimental duplicates for one or more of the purification conditions (+/- RNAse A, +/supplemental $\mathrm{NaCl}$ ). For each prey protein identified, the number of unique peptide spectra recorded was normalized against the number of bait protein peptides recorded; this relative number of unique peptide spectra recorded per protein was used as a metric for semi-quantitative analysis of Nol12-associated proteins.

\section{MS analysis of rNol12}

A total of 1 ug of purified recombinant Nol12 was denatured in $6 \mathrm{M}$ urea, $100 \mathrm{mM}$ ammonium bicarbonate at $37^{\circ} \mathrm{C}$ for 10 minutes, then reduced with $10 \mathrm{mM}$ DTT at $37^{\circ} \mathrm{C}$ for 30 minutes before being alkylated with 16.6mM IAA for $1 \mathrm{~h}$ in the dark at room temperature. Urea was then diluted to $1.6 \mathrm{M}$ and ammonium bicarbonate adjusted to $75 \mathrm{mM}$. Trypsin was added in a 1:20 trypsin:protein ratio and incubated overnight at $37^{\circ} \mathrm{C}$. Next day, the sample was dried using a speedvac, resuspended and cleaned with a ZipTip $\mathrm{C}_{18}$ according to the manufacturer (EMD Millipore) before being analyzed by tandem mass spectrometry as described previously (31).

\section{Northern blotting}

Total RNA from scramble and NOL12 siRNA transfected cells was extracted with TRIzol (Invitrogen) according to the manufacturer's protocol. For long RNA analysis, total RNA were separated on $1 \%$ agarose-formaldehyde gels in Tricine-Triethanolamine and transferred on nylon membrane in 10x SSC by capillarity as described by Mansour and Pestov (32). Small RNAs were separated on $8 \%$ acrylamide-urea gels and transferred on nylon membrane in $0.5 x$ TBE overnight at $12 \mathrm{~V}$. For long rRNA analysis, $3 \mu \mathrm{g}$ of

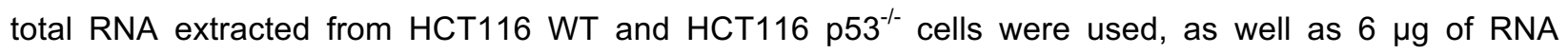
extracted from IMR-90 cells. A total of $8 \mu \mathrm{g}$ of RNA was used for small RNA analysis. All probes used for hybridization are shown in Supplementary Table 8. Probes identified with terminal amines were fluorescently labeled with DyLight ${ }^{\mathrm{TM}} 800$ NHS Ester as previously described (33), while other probes were radiolabeled with $\left[\mathrm{YP}^{32}\right.$ ]ATP (3000 Ci/mmol; Perkin-Elmer).

\section{Cell cycle profiling and quantification of apoptosis}


To profile cell cycle distribution, siRNA- and/or drug-treated cells were harvested by trypsinization at the indicated time points, washed twice with PBS and fixed with $70 \%$ ethanol at $-20{ }^{\circ} \mathrm{C}$ for $>1 \mathrm{~h}$. Fixed cells were rehydrated $2 x$ in PBS then permeabilized, RNAse-treated and stained for DNA content with a modified Krishan Buffer (20 $\mu \mathrm{g} / \mathrm{mL}$ propidium iodide, $0.1 \%$ Triton X-100, $0.2 \mathrm{mg} / \mathrm{mL}$ RNAse A in PBS) for 30 min at RT. Apoptosis was measured using the Annexin V-FITC apoptosis detection kit (Sigma-Aldrich) according to the manufacturer's instructions. Briefly, siRNA- and/or drug-treated cells were harvested at the indicated time points and resuspended at $5 \times 10^{5}$ cells $/ \mathrm{ml}$. Cells were treated with Annexin V-FITC (250 $\mathrm{ng} / \mathrm{ml}$ ) and propidium iodide $(500 \mathrm{ng} / \mathrm{ml})$. In both cases, staining was quantified by flow cytometry and results were analyzed using the FlowJo software.

\section{Detection of oxidized DNA}

siRNA-transfected cells were harvested at the indicated time points and DNA was extracted as previously reported (34). A total $2 \mu \mathrm{g}$ of DNA per sample was spotted onto a nylon membrane and stained with methylene blue, before being digitally scanned to serve as loading control. The membrane was then blocked overnight with $1 \%$ casein in SSC buffer. To detect oxidized guanosines, the membrane was incubated overnight at $4^{\circ} \mathrm{C}$ with an anti-8-OHdG antibody (Millipore). The membrane was then washed 3 times in TBST and incubated with a IRDye $800 \mathrm{CW}$ fluorescently labeled donkey anti-goat secondary antibody diluted 1:15000 in TBST for $1 \mathrm{~h}$. The membrane was finally scanned with a Li-Cor Odyssey infrared scanner. As positive control, a Fenton reaction consisting of $0.5 \mu \mathrm{g} / \mu \mathrm{l}$ genomic DNA was incubated with $25 \mu \mathrm{M} \mathrm{CuSO}_{4}$ and $50 \mathrm{mM} \mathrm{H}_{2} \mathrm{O}_{2}$ for $1 \mathrm{~h}$ at $37^{\circ} \mathrm{C}$.

\section{Immunofluorescence}

siRNA-transfected or doxycycline-induced cells were grown on poly-L-lysine-coated glass coverslips for $48 \mathrm{~h}$ then fixed with $3.2 \%$ paraformaldehyde $(10 \mathrm{~min})$. Cells were washed $2 \mathrm{x}$ with PBS, permeabilized with $0.25 \%$ Triton X-100 in PBS (15 min) and blocked with $1 \%$ BSA in PBS+T (50 mM Tris, $150 \mathrm{mM}$ $\mathrm{NaCl}, 0.05 \%$ Tween-20, $\mathrm{pH} 7.6$ ). The indicated primary antibodies were hybridized for $1 \mathrm{~h}$ in $1 \% \mathrm{BSA}$ in PBS $+\mathrm{T}$, cells were washed $3 \mathrm{x}$ with PBS then rehybridized with the relevant secondary antibody in the same conditions. Coverslips were washed a further $3 x$ with PBS, DNA was stained with Vectashield ${ }^{\circledR}$ 
mounting medium containing DAPI (Vector Laboratories) and imaged using the Zeiss Axioimager Z2 upright epifluorescence microscope with a $63 x$ objective, fitted with the Zeiss Axiocam mRm CCD camera. Images were processed with FIJI open-source image analysis software (35). Traces were generated with the 'Plot Profile' function in Fiji using representative images from each immunofluorescence experiment. Profiles for each channel were normalized against the maximum observed fluorescence value along the line segment and colocalization determined using the Fiji software Coloc2 module.

\section{RESULTS}

\section{Nol12 associates with a diverse interactome}

In order to more thoroughly investigate Nol12's cellular niches, we determined its interactome using Protein A-tagged Nol12 (PrA-Nol12) expressed in HEK293T cells by single-step affinity purification (ssAP) coupled to semi-quantitative mass spectrometry (MS), and analyzed it against untagged and PrAexpressing cell lines (Supplementary Figure 1a) $(31,36)$. The highest total spectrum count values found in the control samples (Untagged, PrA; Supplementary Table 1) were subtracted from that of a PrA-Nol12 sample under the respective condition (100 or $300 \mathrm{mM} \mathrm{NaCl}+/-$ RNAse A). A peptide was considered 'real' in a particular PrA-Nol12 sample (100 or $300 \mathrm{mM} \mathrm{NaCl}+/-$ RNAse A) if the spectrum count value in each replicate was $\geq 2$-fold greater than the highest spectrum count value recorded among the relevant controls under the same purification conditions (Supplementary Tables 1 and 2). The total number of unique peptide spectra recorded for the remaining preys was determined, and preys were defined as Nol12- associated proteins if at least three enriched peptides were identified in both replicates for each condition. For each prey protein identified, the number of unique peptide spectra recorded was normalized against the bait protein peptide count to obtain a number of unique peptide spectra per prey, which was used as a metric for analysis of Nol12-associated proteins. We identified a total of 759 proteins, of which 496 were defined as enriched ( $\geq 3$ peptides in all replicates; Supplementary Table 2). Functional classification of the identified proteins showed a complex interactome and suggested a highly diverse functionality for Nol12 in human cells (Supplementary Tables 3 and 4). 
In line with a putative nucleolar and ribosome biogenesis-associated role, PrA-Nol12-associated preys included 75 ribosome maturation factors required for large ribosomal subunit (LSU) maturation and 54 known 90S pre-ribosomes components, while only 8 proteins specific for small ribosomal subunit (SSU) maturation were identified (Figure 1a). In addition, 42 LSU and 27 SSU ribosomal proteins (RPs) were found (Figure 1a), suggesting a role for Nol12 during LSU maturation events. Comparison of our set of Nol12 interactors with human ribosome biogenesis proteins identified in a recent high-throughput study showed a $58.9 \%(n=158)$ overlap supporting the idea of Nol12 as a ribosome maturation factor (Supplementary Figure 1b) (37). However, PrA-Nol12 also co-isolated a significant number of proteins from several non-ribosomal processes. Those included 51 proteins involved in genome maintenance and integrity (Figure 1a, b: 'Chromatin associated'; Supplementary Table 3), including Dhx9, PRKDC and MYBBP1A. Furthermore, 94 mRNA maturation and turnover factors were identified, including splicing and mRNA maturation factors (e.g. snRNP200, Srsf1, Thoc2, Mrto4), paraspeckle proteins (NONO, SfpQ) as well as components of processing $(P)$ bodies, sites of post-transcriptional mRNA regulation in the cytoplasm (e.g. Stau1, hnRnpA3, Fmr1, LaRP1) (Figure 1a, b: 'mRNA metabolism'; Supplementary Table 3) (1). Moreover, we identified 69 proteins with functions in mitochondria, including many involved in mitochondrial ribosome biogenesis (Figure 1a, b: 'Mitochondria'; Supplementary Table 3). The observation that MRPLs/MRPSs represent low-frequency contaminants in affinity purification experiments argues against these interactions arising from non-specific interactions (Supplementary table 1) (38).

To determine the dependency of Nol12 associations on RNA as well as their stability, we furthermore investigated the Nol12 interactome in the presence of RNase A and/or increased salt. Components of the early (90S) pre-ribosomes were reduced by RNAse digestion, while the majority of LSU maturation factors and RPLs were considerably less sensitive to RNAse treatment (Figure 1a, b; Supplementary Table 3), suggesting an RNA-dependency of Nol12 recruitment to 90 S pre-ribosomes over 60S pre-ribosomes; however, an incomplete RNA digest due to the protection of pre-rRNA within LSU pre-ribosomal complexes cannot be ruled out. LSU maturation factors and RPLs were also considerably stabilized under increased salt conditions (Figure 1b). Of the non-ribosome complexes, only a small number of co-isolated 'RNA metabolism' and 'chromatin-associated' factors showed sensitivity to RNAse treatment, suggesting that most Nol12 interactions in this group are not RNA-dependent (Figure 
$1 \mathrm{~b})$; however, the majority of 'mRNA metabolism' interactors exhibited salt sensitivity compared to the 'chromatin-associated' group, suggesting labile or transient associations of Nol12 with interactors involved in mRNA metabolism.

\section{Nol12 localizes to different subcellular compartments}

Proteomic analysis of Nol12-associated complexes identified both nuclear and cytoplasmic proteins involved in nucleic acid homeostasis, supporting previous high through-put data sets on Nol12 localization (23). To more concretely define these subcellular compartments, we carried out fluorescent microscopy in HCT WT cells using an anti-Nol12 antibody, and compared the protein's localization to that of established markers for different subcellular structures. We found a large fraction of Nol12 localized to nucleoli, with a small amount in the dense fibrillar component (DFC), marked by co-staining for the early ribosomal biogenesis factor Fibrillarin (39), while more Nol12 was found within the granular component (GC), consistent with an 90 S pre-ribosomes association and a role in early LSU maturation (Figure 2a). In addition to its nucleolar localization, Nol12 was also present within numerous discrete foci throughout the nucleoplasm (Figure 2a), some of which showed distinct overlap with the paraspeckle component SfpQ (Figure 2b), concurrent with our AP-MS data (Figure 1a), and consistent with previously observed SfpQ localization patterns $(40,41)$. Further co-staining of Nol12 with markers for different nuclear structures indicated that the protein was most likely not a component of polycomb complexes (Bmi1; Supplementary Figure 2b), Cajal bodies (Coilin; Supplementary Figure 2c), or PML bodies (PML; Supplementary Figure 2d) as no spatial overlap with respective markers was determined using Fiji's Coloc2 module analysis (Materials and Methods). Some partial overlap was found with slicing speckles, (SC35; Supplementary Figure 2a), which could be due to Nol12's localization to paraspeckles, which are found adjacent to splicing speckles (42).

Nol12-associated complexes identified by MS also included cytoplasmic components, in particular GW/P-body proteins (Figure 1a, b). Using an anti-Nol12 antibody, we observed several bright, discrete cytoplasmic foci in HCT116 WT cells (Figure 2a, c), which overlapped with co-staining for Dcp1a, a key component of the mRNA-containing GW/P-bodies, and were significantly increased after treatment 
of cells with arsenite (Figure 2c) (43). Interestingly, under arsenite conditions, Nol12 was not found localized to cytoplasmic stress granules (Tia1; Supplementary Figure 2e). Localization of Nol12 to these various substructures was observed using different anti-Nol12 antibodies, raised against different portions of the protein (Sigma aa130-215; Bethyl aa75-115; data not shown). Taken togther, the localization of Nol12 to different subcellular compartments not only supports our proteomic data, but also suggests multiple functions for the protein.

\section{Nol12 exhibits RNA endonuclease activity in vitro}

The S. cerevisae homologue of Nol12, Rrp17, has previously been shown to possess RNA binding and 5'-3' RNA exonuclease activity (22). To determine whether Nol12 can bind and process RNA, and to better characterize Nol12's role within its diverse interactome, we tested its nuclease activity in vitro using different RNA substrates. Purified recombinant Nol12 (rNol12) was able to degrade a short, uniformly labeled RNA substrate into a ladder of truncated products in a concentration-dependent manner in vitro (Figure 3a). In line with its nuclease activity and high proportion of positively charged residues, Nol12 exhibited RNA binding activity, however, RNA binding was not specific as demonstrated by competition with tRNA (Supplementary Figure 3b). Next, we asked if Nol12 had a specific requirement for divalent cations. Using short, uniformly labeled RNA substrates, the nucleolytic activity of Nol12 was inhibited by replacement of $\mathrm{MgCl}_{2}$ with $\mathrm{MnCl}_{2}$ or pretreatment with EDTA (Figure 3b). To examine direction-dependent degradation, we used an in vitro transcribed single-strand (ss) RNA labeled at its 5' or 3' end. Incubation of rNol12 with 5' end-labeled RNA resulted in a gradual loss of the full-length labeled substrate, however, no accumulation of radiolabeled nucleotide was detected; instead the appearance of radiolabeled products of different lengths was observed (Figure 3c, left). Similar observations were made upon incubation of rNol12 with 3' end-labeled substrate (Figure 3c, right). This suggests that the RNA products are the result of endonucleolytic cleavages rather than end-degradation, which led us to test Nol12 for in vitro endonucleolytic function. Upon incubation of circular radiolabeled ssRNA with rNol12, the circular RNA was linearized producing both a linear ssRNA followed by steady degradation over the course of 30 minutes, resulting in a smear of smaller products (Figure 3d); the appearance of the latter could either be due to unspecific endonucleolytic cleavage, or and additional exonucleolytic activity, which cannot be 
excluded. Taken together, these results suggest that Nol12 has endonucleolytic activity in vitro. However, rNol12 did display low efficiency in vitro; after the exclusion of contaminating nucleases co-purified with rNol12 by mass spectrometry and PAGE analysis (Supplementary Figure 3a; Supplementary Table 5), it suggests that Nol12 may require a co-factor for efficient nuclease function. Finally, given the exonucleolytic activity of the Nol12 yeast homologue Rrp17, a similar activity for Nol12 cannot be complete ruled out; conversely, Rrp17 has never been tested for endonuclease function.

\section{Nol12 is required for rRNA processing at site 2 during ribosome biogenesis}

It has previously been suggested, based on studies in HeLa cells, that Nol12's presence on preribosomes may be required for processing events within the Internal Transcribed Spacer 1 (ITS1) (4). Processing of ITS1 requires three endonucleolytic cleavages; however, only endonucleases for two of these sites, Rcl1 and Nob1, have been identified so far, which act in concert with the exonucleases Xrn2 and Rrp6 $(4,37)$. Given the in vitro endonucleolytic activity of Nol12, we investigated the function of Nol12 in pre-rRNA processing in more detail. HCT116 wild-type (HCT WT) cells were transfected with an siRNA targeting NOL12 transcripts (siNOL12 \#5; referred to as siNOL12 throughout unless otherwise stated) (Figure 4a, lanes 2, 4 and 6), or a scrambled control siRNA (siSCR) (Figure 4a, lanes 1, 3 and 5), and pre-rRNA processing was analyzed by Northern blotting $24 \mathrm{~h}, 36 \mathrm{~h}$ and $48 \mathrm{~h}$ after transfection. Knockdown of NOL12 in HCT WT cells resulted in rRNA processing defects affecting precursors produced by cleavage at site 2 within ITS1: the large subunit precursor 32.5S, and the small subunit pre-rRNAs $30 \mathrm{~S}$, $26 \mathrm{~S}$ and $21 \mathrm{~S}$ were noticeable decreased after $36 \mathrm{~h}$ compared to control (Figure 4a). Conversely, levels of site E cleavage products, namely $36 \mathrm{~S}$ pre-rRNAs, its intermediate processed form $36 \mathrm{~S}-\mathrm{C}$ as well as the small subunit precursor $18 \mathrm{~S}-\mathrm{E}$, were increased as early as $24 \mathrm{~h}$ post siRNA treatment (Figure $4 \mathrm{a}$ ). Mature rRNAs levels were overall only modestly decreased, with LSU rRNAs more affected than SSU ones, suggesting a rerouting of the ribosome maturation pathway to sustain ribosome production. The same modulation of precursors was also observed in IMR-90 primary fibroblasts (Supplementary Figure 4a, lanes 2 and 4), although with differing kinetics most likely due to the cells' overall slower growth rate.

In higher eukaryotes, processing of Pol I-transcribed pre-rRNA occurs along three parallel pathways, presumably to ensure biogenesis of ribosomes (Figure 4b). Pathway 1 and 2, the major 
pathways, require an endonucleolytic cleavage in ITS1 at site 2 to separate SSU and LSU pre-rRNAs (Figure 4b; green and red, respectively), while the alternative, minor pathway 3 produces downstream precursors via endonucleolytic cleavage at site E (Figure 4b; blue) (2). Pre-rRNAs generated upon site 2 cleavage $(30 \mathrm{~S}, 32.5 \mathrm{~S}, 21 \mathrm{~S})$ are all decreased in the absence of Nol12, while pre-rRNAs that are either substrate (41S) for, or products of site E cleavage along pathway 3 (36S and 18S-E) are increased (Figure $4 \mathrm{a}$, arrows). This increase of $41 \mathrm{~S}$ and $18 \mathrm{~S}-\mathrm{E}$, together with a concomitant decrease of $21 \mathrm{~S}$ (product of site 2 cleavage) and appearance of 36S and 36S-C (products of site E cleavage; Figure 4a), indicates that kd of NOL12 leads to an overall decreased cleavage of ITS1 at site 2, and shift of processing events to site E (Figure 4b, blue), suggesting a requirement for Nol12 for processing at site 2. We did not detect reduced processing at site $\mathrm{E}$ or within $5^{\prime} \mathrm{ETS}$, events which have been attributed to the endonuclease Rcl1 and the 5'-3' exonuclease Xrn2, respectively; moreover, the precursors $36 \mathrm{~S}$ and 36SC, which are increased upon NOL12 kd, are known substrates for Xrn2 in mouse and HeLa cells (4). The only marginally lower levels of $5.8 \mathrm{~S}, 18 \mathrm{~S}$ and $28 \mathrm{~S}$ indicate the continued production of mature rRNAs, presumably along pathway 3 , to ensure ribosome biogenesis, suggesting that, in the absence of Nol12, the $36 \mathrm{~S}$ precursor is processed to $32 \mathrm{~S}$ by $\mathrm{Xrn} 2$ following Rcl1 cleavage at site E, albeit with slower kinetics, explaining the accumulation of $41 \mathrm{~S}$ and $36 \mathrm{~S}-\mathrm{C}$, while $32 \mathrm{~S}$ levels are unchanged; 18S-E, also generated by a cleavage site $\mathrm{E}$, is matured to $18 \mathrm{~S}$ rRNA by Nob1 (44). Taken together, and in light of its RNA endonuclease activity shown above, these data suggest Nol12 as the endonuclease required for ITS1 cleavage at site 2 (Figure 4a; Supplementary Figure 4a).

\section{Loss of Nol12 leads to p53-independent cell cycle arrest and apoptosis}

As Nol12 associated with proteins outside ribosome biogenesis and the nucleolus, and ribosome biogenesis was maintained in the protein's absence, we went on to investigate the overall effect of Nol12 depletion on cell proliferation and survival in HCT WT cells to obtain information on its other functional niches. Knockdown of NOL12 resulted in a robust $\mathrm{G}_{1} / \mathrm{S}$ arrest after $36-48 \mathrm{~h}$ (Figure 5a). Strikingly, depletion of Nol12 also induced a strong apoptotic response within 36-48h of siRNA transfection, as evidenced by both increased annexin $\mathrm{V}$ binding without concurrent propidium iodide infiltration (Figure 
$5 b$ ), and by proteolytic activation of caspase 3 (Figure 5c). This rapid onset of apoptosis is highly atypical of rRNA maturation factor depletion (37), and, by comparison, knockdown of the multifunctional 5'-3' exonuclease and ribosome processing factor XRN2 induced only a subtle $G_{1} / S$ delay within $24 h$ of siRNA treatment (Figure 5a), and no apoptotic response (Figure 5c) suggesting that the observed apoptotic was not due to Nol12's role in ribosome biogenesis. Analysis of HCT WT whole cell lysates by western blotting revealed that depletion of Nol12, but not Xrn2, resulted in progressive accumulation of the key cell cycleand apoptosis-regulatory protein $\mathrm{p} 53$, as well as $\mathrm{p} 21^{\mathrm{WAF} 1 / \mathrm{CIP} 1}$ and $\mathrm{p} 27^{\mathrm{KIP} 1}$ (Figure $5 \mathrm{~d}$ ). These changes coincided with downregulation of S-phase-promoting phosphorylation of $\mathrm{Rb}$ and increased phosphorylation of p53 on Ser15, a stabilizing modification by PIKK-family kinases (ATM, ATR and DNAPK) in response to DNA damage (Figure 5d) (45), suggesting that loss of Nol12 elicits significant cellular stress, activating both cell cycle arrest and apoptosis response pathways, despite its modest effect on ribosome biogenesis.

Recent data has shown that loss of several ribosome biogenesis factors or ribosomal proteins triggers 'nucleolar stress' via accumulation of free 5S RNP (5S rRNA, Rpl5 and Rpl11) in the nucleoplasm, leading to inhibition of ribosome biogenesis and downregulation of the p53-ubiquitin E3 ligase Mdm2. This leads to subsequent p53 accumulation and cell cycle arrest, thus providing cells with a surveillance mechanism for monitoring ribosomal integrity (46). Nol12 depletion did not result in accumulation of nuclear Rpl11 (data not shown), suggesting that NOL12 kd-induced cell cycle arrest and apoptosis may not be part of a nucleolar stress response. To determine whether NOL12 kd-mediated $\mathrm{G}_{1} / \mathrm{S}$ arrest and apoptosis are dependent on p53 stabilization, Nol12 was depleted in HCT116 cells lacking functional p53 (HCT116 $\left.p 53^{-/-}(47)\right)$. Both apoptosis (Figure $5 e$ ) and $\mathrm{G}_{1} / \mathrm{S}$ arrest (Figure $5 f$ ) were identical to $\mathrm{p}^{+} 3^{+/+}$cells upon loss of Nol12, while no cell cycle delay was detected upon XRN2 kd (Figure 5f). Pre-rRNA maturation defects upon NOL12 kd in the absence of p53 were identical to those observed in HCT WT cells (Supplementary Figure 4b), consistent with previous reports regarding ribosome biogenesis in p53-deficient cells (37). Similar results were obtained when Nol12 and p53 were codepleted in HCT WT cells (Supplementary Figure $5 a$ ), suggesting that the $G_{1} / S$ delay and apoptosis observed upon NOL12 kd are not dependent on p53 signaling. 
While p53-dependent pathways represent the major effector mechanisms of nucleolar stress, $\mathrm{p} 21^{\mathrm{WAF} 1 / \mathrm{CIP} 1}, \mathrm{p} 27^{\mathrm{KIP} 1}$ and c-myc were previously shown to activate nucleolar stress-dependent cell cycle arrest in a p53-independent manner (46). Indeed in HCT116 $p 53^{-/-}$cells, p2 $1^{\mathrm{WAF} 1 / \mathrm{CIP} 1}$ and $\mathrm{p} 27^{\mathrm{KIP} 1}$ were both upregulated following NOL12 kd (Figure 5g), while c-myc, another target of Rpl11, was unaltered in both HCT WT and $p 53^{-/}$cells (Supplementary Figure $5 \mathrm{~b}, \mathrm{c}$ ) (46). However, co-depletion of Nol12 and either $\mathrm{p} 21^{\mathrm{WAF} 1 / \mathrm{CIP} 1}$ or $\mathrm{p} 27^{\mathrm{KIP} 1}$ in $\mathrm{HCT} p 53^{-/}$cells (Supplementary Figure $5 \mathrm{~d}$ ), or of Nol12, p53 and either $\mathrm{p} 21^{\mathrm{WAF} 1 / \mathrm{CIP} 1}$ or $\mathrm{p} 27^{\mathrm{KIP} 1}$ in HCT WT cells failed to rescue $\mathrm{G}_{1} / \mathrm{S}$ arrest (Supplementary Figure $5 \mathrm{a}$ ), suggesting that the observed cell cycle arrest, and apoptosis response, upon Nol12 depletion are neither p53 nor c-myc dependent as well as independent of p21 or p27, and thus qualitatively distinct from a nucleolar stress response. Interestingly, while we did observe downregulation of Mdm2 after loss of Nol12, increased amounts of the phosphorylated form Mdm2 ${ }^{\mathrm{pS} 166}$ were detected in NOL12 kd (Figure $5 \mathrm{~d}$ ), and more mildly in HCT116 $p 53^{--}$cells (Figure $5 \mathrm{~g}$ ), but not XRN2 kd cells (Figure $5 \mathrm{~d}$ ). Mdm2 $2^{\mathrm{pS} 166}$ is an activating phosphorylation mediated by p-Akt upon oxidative stress that propagates p53 degradation; however, binding of $M d m 2^{\mathrm{pS} 166}$ to $\mathrm{p} 53$ is blocked by p53-phosphorylation on Ser15/Ser20. Upon increased oxidative stress and $M d m 2^{\mathrm{pS} 166}$ phosphorylation, $\mathrm{p} 53^{\mathrm{pS} 15}$ is degraded, an effect also observed upon NOI12 kd in HCT WT cells after $48 \mathrm{~h}$ (Figure $5 \mathrm{~d}$ ), suggesting that activation of $\mathrm{p} 53^{\mathrm{pS} 15}$ and activation of $\mathrm{Mdm} 2^{\mathrm{pS} 166}$ are caused by different upstream events and effectors, and may activate different downstream pathways $(45,48)$.

\section{Nol12-induced apoptosis is dependent on the DNA damage-sensing kinase ATR}

The induction of a robust, p53-independent apoptosis following Nol12 depletion is highly unusual for a ribosome biogenesis factor, supporting the notion that Nol12 may possess non-ribosomal functions, which are responsible for this apoptotic response. The phosphorylation of p53 on Ser15, an event associated with the activity of the DNA damage-sensing PIKK-family kinases ATM, ATR and DNA-PK, and Mdm2 on Ser166, an event mediated by p-Akt1 upon oxidative stress, following Nol12 depletion, led us to examine the activation of DNA damage response (DDR) pathways. Western analysis of whole cell lysates from NOL12 kd cells revealed the induction of signaling cascades typically associated with a DDR 
(Figure 6a). Phosphorylation of the variant histone H2A.X on Ser139, an early event in DNA damage recognition, was increased after $24 \mathrm{~h}$, an effect also seen upon kd of XRN2 but to a lesser extent. NOL12 kd also resulted in robust and rapid phosphorylation of Chk1 on Ser345 after only 24hr, indicating activation of the ATR kinase (Figure 6a), while only a mild increase in phosphorylation of Chk2 at Thr68 and a decrease of Chk2 ${ }^{\text {pSer19 }}$, targets of DNA-PK and ATM kinases, respectively, were observed, suggesting that loss of Nol12 triggers activation of the ATR-Chk1 arm of the DDR cascade, and, to a lesser extent, ATR-Chk2 (49).

ATM, DNA-PK and ATR are activated by different DNA damage signals. ATM and DNA-PK recognize double-strand breaks (DSBs), while ATR recognizes regions of single-strand DNA that arise from a range of insults including single-strand breaks (SSBs), DNA oxidation and stalled replication forks; however, some cross-talk between the pathways exists $(50,51)$. In order to investigate the relationship between ATM, ATR and DNA-PK and Nol12 function, HCT WT cells transfected with siSCR or siNOL12 were grown in the presence of specific inhibitors of ATM (KU55933), ATR (VE822) and DNA-PK (NU7441) (52-54). Cells were assayed for apoptosis $24 \mathrm{~h}, 36 \mathrm{~h}$ and $48 \mathrm{~h}$ post-knockdown as previously described. While neither KU55933 nor NU7441 affected the induction of apoptosis following NOL12 kd, treatment with VE822 reduced the apoptotic response to that of background (i.e. siSCR + VE822; Figure 6b). Dose-response analyses revealed that VE822 inhibited NOL12 kd-dependent apoptosis with an IC ${ }_{50}$ of $92.2 \mathrm{nM}\left(\mathrm{R}^{2}=0.982\right)$, 4.9-fold higher than the published $\mathrm{IC}_{50}$, while KU55933, for comparison, inhibited apoptosis by only $38 \%$ at the highest concentration tested $\left(20 \mu \mathrm{M}, 1550\right.$-fold over the published $\left.\mathrm{IC}_{50}\right)$. Next we tested the relation of NOL12 kd-induced apoptosis to Chk1 and Chk2, the kinases downstream of ATM and ATR. Surprisingly, treatment with the Chk1-inhibitor ChiR124 did not reduce the apoptotic response upon NOL12 kd (Figure 6c, middle), while treatment with the Chk2-inhibitor NSC109555 led to a mild reduction (Figure $6 \mathrm{c}$, right) $(55,56)$. These results suggest that, while NOL12 kd-induced apoptosis requires signaling via ATR, it may do so independently of Chk1, despite leading to its phosphorylation; instead, apoptosis upon loss of Nol12 appears to be dependent on signaling via Chk2. Importantly, knockdown of the ribosomal protein gene, RPS6, did not result in an apoptotic response and was insensitive to VE822 treatment, confirming that the NOL12 kd-related apoptotic response is unlikely the result of ribosomal stress (Figure 6d). Overall, these data suggests that Nol12 may function in an ATR- 
induced DNA damage response, which is supported by a lack of co-localization of Nol12 with the ATMactivated DNA double-strand break marker 53BP1 in HCT WT cells, both in absence and presence of $1 \mu \mathrm{g} / \mathrm{mL}$ Actinomycin $\mathrm{D}(\mathrm{ActD})$, which intercalates into DNA and induces double-strand breaks (data not shown) (57).

Given that the cell cycle arrest arising from NOL12 kd was resistant to inhibition of nucleolar stress pathways, we tested whether it too was dependent on DNA damage signaling. To this end, we carried out cell cycle profiling experiments in the presence of caffeine, a PIKK kinase inhibitor that targets both ATM and ATR, and the DNA-PK inhibitor NU7441 (58). Consistent with observations described above, the $<2 \mathrm{n}$ cell cycle population (consisting of apoptotic/necrotic cells and cell debris) was significantly decreased in the presence of caffeine but not NU7441 (Figure 6e), as was the total apoptotic cell count (Supplementary Figure $5 e$ ). However, the induction of $G_{1} / S$ arrest was unchanged in the presence of either caffeine or NU7441 (Figure 6e), suggesting that the cell cycle arrest and apoptotic phenotypes of NOL12 kd arise by different mechanisms and, possibly, different upstream events.

\section{Loss of Nol12 leads to increased DNA oxidation}

The activation of the ATR-Chk1/Chk2 DNA damage pathway and ATR-dependent apoptosis by NOL12 kd led us to re-examine the interactome of PrA-Nol12 with regards to a possible role on damaged DNA. Indeed, PrA-Nol12 co-isolated numerous proteins implicated in DNA damage response and repair pathways. In particular, PRKDC, the catalytic component of DNA-PK, and Dhx9, a multifunctional nuclear helicase that resolves R- and D-loops and is excluded from the nucleolus in most cells, were both coisolated in high quantities in all tested conditions (23). Nol12 also co-isolated high amounts of NONO and SfpQ (Figures 1a and 7a), two mRNA processing factors and paraspeckle components that are recruited to sites of DNA damage, and co-localized with SfpQ (Figure 2b) $(59,60)$. Association of Nol12 with DNAPK, Dhx9 and NONO was not RNA dependent, suggesting either a DNA-related role or association with these proteins prior to assembly on target RNA; however, with the exception of Dhx9, most associations in this group, including DNA-PK and NONO, were salt-sensitive, suggesting transient or labile 
interactions. Interestingly, while Nol12 partially co-localized with SfpQ to paraspeckles, upon treatment with ActD at a concentration that specifically inhibits RNA Pol I but not RNA Pol II $(0.05 \mu \mathrm{g} / \mathrm{mL}, 3 \mathrm{~h})$ inducing to the formation of nucleolar caps, unlike SfpQ, Nol12 did not retreat into nucleolar caps, but instead formed a peripheral nucleolar ring while still maintaining its presence within nucleoplasmic foci and the cytoplasm (Figure 7b). Nol12 also co-localized with Dhx9, and overlap of foci was increased upon ActD treatment at concentrations known to affect overall genomic stability $(1 \mu \mathrm{g} / \mathrm{mL}, 3 \mathrm{~h})$, suggesting, in line with our proteomic data, a potential co-function for Nol12 in genome instability management (Figure 7c).

Given the above data, we assayed whether loss of Nol12 was able to accumulate DNA damage sufficient to activate the ATR pathway. Total cellular DNA from HCT WT cells treated with control siSCR, or two different NOL12 siRNAs (siNOL12 \#5 and \#8) was probed by southwestern blotting with an antibody against 8-hydroxydeoxyguanosine (8-OHdG), a form of oxidative DNA damage shown to predominantly activate ATR-associated DDR (49). Strikingly, 8-OHdG was significantly accumulated in cellular DNA 24-36h after Nol12 depletion (Figure 7d, e), suggesting that Nol12 may be required for protection against 8-OHdG formation in this cell line. This induction of oxidative stress is in accordance with the observed activation of $M d m 2^{\mathrm{pS} 166}$ (Figure $5 \mathrm{~d}, \mathrm{~g}$ ), which accumulates in an MEK-ERK-dependent manner upon $\mathrm{H}_{2} \mathrm{O}_{2}$ treatment (48). As this data implies a possible role for Nol12 in protection from DNA damage or in DNA repair, we tested whether the protein, in addition to possessing RNA endonuclease activity, was also able to metabolize DNA substrates in vitro. Similar to RNA substrates, incubation of rNol12 with end-labeled, linear ssDNA and dsDNA substrates resulted in the appearance of labeled products of different lengths while no accumulation of radio-labeled nucleotide was observed, consistent with endonucleolytic cleavage of the substrate (Figure 7f). In addition, incubation of rNol12 with ligated, circular radiolabeled dsDNA resulted in linearization of the circular DNA, producing a linear ssDNA by endonucleolytic cleavage and a smear of smaller products over the course of 30 minutes (Figure $7 \mathrm{~g}$ ). These data support an endonucleolytic activity for Nol12 on DNA, identifying it as a RNA/DNA endonuclease in vitro with a role in the prevention or repair of DNA oxidation in vivo. 


\section{DISCUSSION}

We show here that the human protein Nol12 is a RNA/DNA endonuclease required for both ribosome maturation and genome maintenance in higher eukaryotes. Nol12 is part of early $90 \mathrm{~S}$ and pre-60S ribosomal subunits in vivo, where it is required for efficient separation of the large and small subunit precursors via cleavage at site 2 . Knockdown of NOL12 impairs cellular proliferation by inducing a $\mathrm{G}_{1} / \mathrm{S}$ cell cycle arrest, but does so outside of a nucleolar stress response and in a p53 and c-myc-independent manner. In addition, Nol12 has a putative role in the prevention and/or resolution of DNA oxidation as loss of the protein leads to an increase in oxidized DNA levels followed by a rapid activation of the DNA damage response kinase ATR and apoptotic response. Moreover, Nol12 interacts with a number of chromatin-associated factors in vivo, in particular proteins implicated in DNA damage repair, and colocalizes with paraspeckle component SfpQ, and the RNA/DNA DEAD-box helicase Dhx9, involved in genome instability prevention, suggesting further roles in genome maintenance. Nol12 is also associated with RNA metabolism pathways outside of ribosome biogenesis, namely in P-bodies, which is supported by both proteomic data and its co-localization with Dcp1a.

\section{Nol12, the nucleolus, ribosome biogenesis and cell growth}

Redundant ribosome maturation pathways are considered vital to sustain ribosome levels and, in higher eukaryotes, this link is emphasized by the fact that loss of most ribosome biogenesis factors leads to a cell cycle arrest in $G_{1} / S$, which is always preceded by the appearance of rRNA processing defects; however, while the $G_{1} / S$ arrest is part of a nucleolar stress response, it rarely leads to apoptosis in a majority of cell types (37). Our characterization of Nol12's role in pre-rRNA processing revealed the protein to be required for cleavage at site 2 as all immediate precursors resulting from cleavage at this site - $30 \mathrm{~S}$ and $21 \mathrm{~S}$, but mostly $32.5 \mathrm{~S}$ - are significantly reduced in the absence of Nol12. Given its in vitro endonuclease activity our data suggests that Nol12 may be the as yet unidentified site 2 endonuclease. In its absence the pathway is rerouted through site $\mathrm{E}$ as indicated by the increase in $36 \mathrm{~S}$ and subsequent Xrn2-processed intermediates (36S-C), presumably to ensure ribosome production, which is supported by the moderate effect on mature rRNA levels. A role for Nol12 as the site 2 endonuclease is strongly 
supported by the Nol12 pre-ribosome interactome, in particular, the significant enrichment of Utp10, Rrp5, Ftsj3, Gtpbp4, and Rsl1D1 (Supplementary Table 3). The association with a high number of 90S factors suggests an early recruitment of Nol12 to pre-rRNA as Utp10 is a t-UTP factor that was suggested to be one of the earliest proteins to associate with the 47S precursor (61). The RNA binding protein Rrp5 was recently shown to be important for both cleavage at site 2 and processing from site 2 to E by Rrp6 (4), while loss of Ftsj3 delayed processing at site 2, shifting events to the minor pathway via site $E$ (62). It is conceivable that these proteins either aid in the recruitment of Nol12 to pre-ribosomes, or facilitate Nol12's function at site 2, possibly even through direct interaction. Nothing is known about the roles of RsI1D1 and Gtpbp4 in pre-rRNA processing, yet their depletion results in a similar pattern of precursors than those observed upon loss of Nol12, suggesting a function in or around the same processing events (37). Rcl1, the endonuclease responsible for cleavage at site $\mathrm{E}$, and $\mathrm{Xrn} 2$ were co-isolated at very low levels, supporting the notion that they function along a different yet parallel pathway than Nol12 (4). Inconclusive results of previous studies on Nol12's role in ITS1 processing were most likely due to the fact that processing events were surveyed $60 \mathrm{~h}$ after siRNA transfection, at which point significant levels of apoptosis can be observed in Nol12-depleted cells (4).

However, besides rerouting of processing events, loss of Nol12 also elicits a strong $\mathrm{G}_{1} / \mathrm{S}$ arrest independent of both p53 and c-myc signaling, and outside a typical nucleolar stress response. Moreover, the scale of the arrest is markedly more severe compared, for example, to that observed upon Xrn2 depletion, while decrease in mature rRNAs, and subsequently ribosomes, is much less severe to knockdowns of other maturation factors, or to warrant the strong and rapid onset of apoptosis in the absence of Nol12 $(4,37,63)$. It is therefore likely that Nol12 has other essential cellular functions outside the nucleolus.

\section{A role for Nol12 in the maintenance of genome integrity}

In Drosophila, kd of the NOL12-homologue Viriato resulted in loss of cell proliferation and apoptosis (20, 64). Oxidative stress, and in particular the production of reactive oxygen species (ROS), is a known 
contributor to cellular damage, including oxidative DNA damage, and, if not repaired, leads to subsequent cell death (49). The accumulation of $8-\mathrm{OHdG}$ after 24-36h in Nol12-depleted cells is likely the cause for the observed apoptotic response $36-48 \mathrm{~h}$ post-siRNA treatment. This notion is supported by the activation of the ATR-Chk1/2 DDR pathway and phosphorylation of Chk1 $1^{\mathrm{pS} 345}, \mathrm{Mdm}^{\mathrm{pS} 166}$ and Chk2 ${ }^{\mathrm{pT} 68}$ observed after $24 \mathrm{~h}$, and the decrease in $\mathrm{p} 53^{\mathrm{pS} 15}$ levels at $48 \mathrm{~h}$, most likely allowing for $\mathrm{Mdm} 2^{\mathrm{pS} 166}$-triggered degradation of p53 $(48,49)$. Moreover, this rapid activation of the DDR pathway suggests this to be a direct cause upon loss of Nol12. ATR-Chk1-mediated apoptosis has previously been observed upon replicative stress via ribonucleotide reductase inhibition, interstrand cross-links, oxidative or base damage of DNA, amongst others (50). Moreover, the abolition of apoptosis, but not $\mathrm{G}_{1} / \mathrm{S}$ arrest, upon ATR inhibition fully supports an oxidative stress induced apoptosis, and further suggests that these two responses, $G_{1} / S$ arrest and cell death, likely arise from different primary stimuli. The observed interactions of Nol12 with DNA damage factors, its localization to transcription-independent nucleoplasmic granules, co-localization with Dhx9, and its ability to endonucleolytically cleave dsDNA all raise the possibility that Nol12 may act directly on damaged DNA. Similarly, Nol12 could either support the resolution of sites of oxidized DNA and/or suppress oxidized DNA formation; loss of either activity would trigger the ATR pathway. Alternatively, the cause of increased DNA oxidation could also be due to the increased generation of ROS, possibly through perturbation of mitochondrial function. The Nol12 interactome contains a significant number of proteins found in the mitochondria (Supplementary Table 3). In particular, a marked enrichment is seen for protein components of the mitochondrial ribosome (MRPLs/MRPSs; (65)) and of proteins found in the mitochondrial nucleoid, the mitochondrial DNA-protein complex containing the mitochondrial genome and proteins required for DNA replication, stability, transcription and early rRNA processing (66). This indicates the possibility that Nol12 may possess functions in DNA repair or ribosome biogenesis within the mitochondria. Loss of these functions would lead to mitochondrial dysfunction and, ultimately, increased intracellular ROS and apoptosis (67). This notion is supported by recent findings of Nol12 interacting with superoxide dismutase 2 (SOD2) (68), an enzyme that catalyzes ROS in mitochondria, limiting their detrimental effects in an anti-apoptotic role against oxidative stress, as well as the neuron-expressed cytosolic protein p33Monox, inhibitor of APP and Bcl2 phosphorylation (24), and APP itself (69). Taken together this may suggest a role for Nol12 in prevention of oxidative damage 
in neurons. Finally, Nol12 may also act on oxidized RNA, and to date no known definitive enzyme for the repair of oxidized RNA has been identified (18); however, such function remains to be determined.

\section{Nol12, a nuclease with diverse cellular roles}

Multifunctional nucleases are common in many organisms. In higher eukaryotes, the multifunctional RNA exonucleases Xrn2 and hRrp6, were recently shown to aid in the resolution of RNA:DNA hybrids and repair of DNA double-strand breaks, respectively, expanding their functions beyond the RNA realm (13, 14); this function of $\mathrm{Xrn} 2$ is also the most likely cause for the phosphorylation H2A. $X^{\mathrm{pS} 139}$ observed in its absence. The endonuclease Dicer was shown to process both miRNAs and siRNAs, while also functioning during DNA damage repair $(8,15)$, and the human AP endonuclease 1 (APE1) was previously characterized as a multifunctional enzyme: a major component of the DNA base-excision repair pathway and responsible for decay of c-myc mRNA (8). The co-isolation of components from diverse cellular RNA/DNA homeostasis niches, its localization to different subcellular compartments as well as its RNA and DNA endonuclease activity supports the idea of Nol12 as another multifunctional nuclease. Nol12 has also been identified in several recent high-throughput screens for mRNA-binding proteins $(70,71)$, and, here, we found the protein was localized to GW/P-bodies under normal growth conditions as well as enriched upon arsenite stress, suggesting a putative role in mRNA metabolism. Moreover, Nol12's association and co-localization with paraspeckle components suggests a potential function within these bodies, either in the cleavage of the 566 adenosine-to-inosine edited Alu-repeat containing human RNAs, as no endonuclease for this function has been identified to date, or during DNA damage $(72,73)$. Both possibilities will be investigated in the future.

Being a broad-specificity RNA/DNA nuclease, Nol12's multifunctionality is likely to be conveyed through either different cofactors such as helicases, which would also explain its low in vitro nuclease activity, and/or posttranslational modifications (PTMs). A casein kinase II target site has been identified at S134 within both Nol12 and its mouse homologue Nop25, and both the CKII subunit CSNK2A1 and the phosphatase PP1A are part of the Nol12 proteome (Supplementary Table 3). Moreover, several helicases 
were found significantly enriched with Nol12, including Ddx21, which is involved in both transcription and rRNA processing (74), the GW/P-body proteins Ddx5 and Ddx17 (75), and the multifunctional RNA/DNA helicase Dhx9, implicated in the resolution of numerous aberrant DNA structures including triple-helices, G-quadruplexes, D-loops and, most significantly, RNA:DNA hybrids (76). Dhx9 has also been shown to co-localize with H2A.X ${ }^{\mathrm{pS} 139}$ and DNA-PK in RNA-containing granules upon exposure of cells to low-dose actinomycin $\mathrm{D}$ and to protect $\mathrm{E} \mu-m y c / \mathrm{Bcl}-2$ lymphoma cells against an ATR-dependent apoptotic response (77), suggesting it may be required for the resolution of stalled RNA polymerases and/or the resulting RNA:DNA hybrids. Two other Nol12 interactors, SUPT16H and SSRP1, have also been implicated in R-loop resolution in humans (78). Hence, a role for Nol12 in the resolution of unusual DNA structures or RNA:DNA hybrids in concert with Dhx9 would provide another attractive explanation for the activation of an ATR-dependent apoptotic response following Nol12 depletion. The recent identification of RNA processing proteins in the DNA damage response by a number of screens, speaks for a functional juncture between RNA metabolism and DNA repair pathways (19). Overall, the putative multifunctionality of Nol12 presents one such protein at the intersection of RNA metabolism and DNA maintenance and repair, and it will be interesting to explore the mechanisms of its different functions in the future.

\section{ACKNOWLEDGMENTS}

The authors thank Drs. J. Archambault, N. Francis, E. Lecuyer, F. Robert, N. Watkins, and D. Zenklusen for gifts of reagents used in this study, Dr. C. Denicourt for cell lines, S. Rahman and P. Raymond for assistance with microscopy, D. Faubert of the IRCM Proteomics platform, and members of the Oeffinger and Zenklusen labs for critical reading.

\section{FUNDING}

This work was supported by operating grants from the Canadian Institutes of Health Research (MOP 106628-MO); the Natural Sciences and Engineering Research Council of Canada (RGPIN 386315-MO); and Fonds de recherche du Québec - Santé (PR2I). M.O. holds a CIHR New Investigator award and 
Fonds de recherche du Québec - Santé Chercheur Boursier Junior I. Funding for open access charge: Natural Sciences and Engineering Research Council of Canada.

\section{REFERENCES}

1. Singh,G., Pratt,G., Yeo,G.W. and Moore,M.J. (2015) The Clothes Make the mRNA: Past and Present Trends in mRNP Fashion. Annu Rev Biochem, 84, 325-354.

2. Henras,A.K., Plisson-Chastang,C., O'Donohue,M.-F., Chakraborty,A. and Gleizes,P.-E. (2014) An overview of pre-ribosomal RNA processing in eukaryotes. Wiley Interdiscip Rev RNA, 10.1002/wrna.1269.

3. Miki,T.S. and Großhans,H. (2013) The multifunctional RNase XRN2. Biochem Soc Trans, 41, 825-830.

4. Sloan,K.E., Mattijssen,S., Lebaron,S., Tollervey,D., Pruijn,G.J.M. and Watkins,N.J. (2013) Both endonucleolytic and exonucleolytic cleavage mediate ITS1 removal during human ribosomal RNA processing. J Cell Biol, 200, 577-588.

5. Pefanis,E., Wang,J., Rothschild,G., Lim,J., Kazadi,D., Sun,J., Federation,A., Chao,J., Elliott,O., Liu,Z.P., et al. (2015) RNA exosome-regulated long non-coding RNA transcription controls super-enhancer activity. Cell, 161, 774-789.

6. Szczepińska,T., Kalisiak,K., Tomecki,R., Labno,A., Borowski,L.S., Kulinski,T.M., Adamska,D., Kosinska,J. and Dziembowski,A. (2015) DIS3 shapes the RNA polymerase II transcriptome in humans by degrading a variety of unwanted transcripts. Genome Res, 25, 1622-1633.

7. Kiss,D.L., Hou,D., Gross,R.H. and Andrulis,E.D. (2012) Dis3- and exosome subunit-responsive 3' mRNA instability elements. Biochem Biophys Res Commun, 423, 461-466.

8. Tomecki,R. and Dziembowski,A. (2010) Novel endoribonucleases as central players in various pathways of eukaryotic RNA metabolism. RNA, 16, 1692-1724.

9. Lebreton,A., Tomecki,R., Dziembowski,A. and Seraphin,B. (2008) Endonucleolytic RNA cleavage by a eukaryotic exosome. Nature, 456, 993-996.

10. Schneider,C., Leung,E., Brown,J. and Tollervey,D. (2009) The N-terminal PIN domain of the exosome subunit Rrp44 harbors endonuclease activity and tethers Rrp44 to the yeast core exosome. Nucleic Acids Res, 37, 1127-1140.

11. Tomecki,R., Kristiansen,M.S., Lykke-Andersen,S., Chlebowski,A., Larsen,K.M., Szczesny,R.J., Drazkowska,K., Pastula,A., Andersen,J.S., Stepien,P.P., et al. (2010) The human core exosome interacts with differentially localized processive RNases: hDIS3 and hDIS3L. The EMBO Journal, 29, 2342-2357.

12. Paulsen,R.D., Soni,D.V., Wollman,R., Hahn,A.T., Yee,M.-C., Guan,A., Hesley,J.A., Miller,S.C., Cromwell,E.F., Solow-Cordero,D.E., et al. (2009) A genome-wide siRNA screen reveals diverse cellular processes and pathways that mediate genome stability. Mol Cell, 35, 228-239.

13. Marin-Vicente,C., Domingo-Prim,J., Eberle,A.B. and Visa,N. (2015) RRP6/EXOSC10 is required for the repair of DNA double-strand breaks by homologous recombination. J Cell Sci, 128, 1097-1107. 
14. Skourti-Stathaki,K., Proudfoot,N.J. and Gromak,N. (2011) Human senataxin resolves RNA/DNA hybrids formed at transcriptional pause sites to promote Xrn2-dependent termination. Mol Cell, $\mathbf{4 2}$, 794-805.

15. Liu,B., Liu,M., Wang,J., Zhang,X., Wang,X., Wang,P., Wang,H., Li,W. and Wang,Y. (2015) DICERdependent biogenesis of let-7 miRNAs affects human cell response to DNA damage via targeting p21/p27. Nucleic Acids Res., 43, 1626-1636.

16. Swahari,V., Nakamura,A., Baran-Gale,J., Garcia,I., Crowther,A.J., Sons,R., Gershon,T.R., Hammond,S., Sethupathy,P. and Deshmukh,M. (2016) Essential Function of Dicer in Resolving DNA Damage in the Rapidly Dividing Cells of the Developing and Malignant Cerebellum. Cell Rep, 14, 216-224.

17. Boisvert,F.-M., van Koningsbruggen,S., Navascués,J. and Lamond,A.I. (2007) The multifunctional nucleolus. Nat Rev Mol Cell Biol, 8, 574-585.

18. Antoniali,G., Lirussi,L., Poletto,M. and Tell,G. (2014) Emerging roles of the nucleolus in regulating the DNA damage response: the noncanonical DNA repair enzyme APE1/Ref-1 as a paradigmatical example. Antioxid. Redox Signal., 20, 621-639.

19. Montecucco,A. and Biamonti,G. (2013) Pre-mRNA processing factors meet the DNA damage response. Front Genet, 4, 102.

20. Marinho,J., Casares,F. and Pereira,P.S. (2011) The Drosophila Nol12 homologue viriato is a dMyc target that regulates nucleolar architecture and is required for dMyc-stimulated cell growth. Development, 138, 349-357.

21. Suzuki,S., Fujiwara,T. and Kanno,M. (2007) Nucleolar protein Nop25 is involved in nucleolar architecture. Biochemical and Biophysical Research Communications, 358, 1114-1119.

22. Oeffinger,M., Zenklusen,D., Ferguson,A., Wei,K.E., Hage,El,A., Tollervey,D., Chait,B.T., Singer,R.H. and Rout,M.P. (2009) Rrp17p is a eukaryotic exonuclease required for 5' end processing of Pre-60S ribosomal RNA. Mol Cell, 36, 768-781.

23. Uhlén,M., Fagerberg,L., Hallström,B.M., Lindskog,C., Oksvold,P., Mardinoglu,A., Sivertsson,A., Kampf,C., Sjöstedt,E., Asplund,A., et al. (2015) Proteomics. Tissue-based map of the human proteome. Science, 347, 1260419-1260419.

24. Mishra,M., Inoue,N. and Heese,K. (2011) Characterizing the novel protein p33MONOX. Mol Cell Biochem, 350, 127-134.

25. Rout,M., Aitchison,J., Suprapto,A., Hjertaas,K., Zhao,Y. and Chait,B. (2000) The yeast nuclear pore complex: composition, architecture, and transport mechanism. J Cell Biol, 148, 635-51.

26. Trahan,C. and Dragon,F. (2009) Dyskeratosis congenita mutations in the H/ACA domain of human telomerase RNA affect its assembly into a pre-RNP. RNA, 15, 235-243.

27. Lang,K. and Micura,R. (2008) The preparation of site-specifically modified riboswitch domains as an example for enzymatic ligation of chemically synthesized RNA fragments. Nat Protoc, 3, 1457-1466.

28. Frommer,J., Hieronymus,R., Selvi Arunachalam,T., Heeren,S., Jenckel,M., Strahl,A., Appel,B. and Müller,S. (2014) Preparation of modified long-mer RNAs and analysis of FMN binding to the ypaA aptamer from B. subtilis. RNA Biol, 11, 609-623.

29. Domanski,M., Kelly,M., Jiang,H., Chait,B.T., Rout,M.P., Jensen,T.H. and John,L. (2012) Improved 
methodology for the affinity isolation of human protein complexes expressed at near endogenous levels. BioTechniques, 10.2144/000113857.

30. Gingras,A.-C., Gstaiger,M., Raught,B. and Aebersold,R. (2007) Analysis of protein complexes using mass spectrometry. Nat Rev Mol Cell Biol, 8, 645-654.

31. Oeffinger,M., Wei,K.E., Rogers,R., Degrasse,J.A., Chait,B.T., Aitchison,J.D. and Rout,M.P. (2007) Comprehensive analysis of diverse ribonucleoprotein complexes. Nat Methods, 4, 951-956.

32. Mansour,F.H. and Pestov,D.G. (2013) Separation of long RNA by agarose-formaldehyde gel electrophoresis. Anal Biochem, 441, 18-20.

33. Rahman,S. and Zenklusen,D. (2013) Single-molecule resolution fluorescent in situ hybridization (smFISH) in the yeast S. cerevisiae. Methods Mol Biol, 1042, 33-46.

34. Wang,T.Y., Wang,L., Zhang,J.H. and Dong,W.H. (2011) A simplified universal genomic DNA extraction protocol suitable for PCR. Genet. Mol. Res., 10, 519-525.

35. Schindelin,J., Arganda-Carreras,I., Frise,E., Kaynig,V., Longair,M., Pietzsch,T., Preibisch,S., Rueden,C., Saalfeld,S., Schmid,B., et al. (2012) Fiji: an open-source platform for biological-image analysis. Nat Meth, 9, 676-682.

36. Trahan,C., Aguilar,L.-C. and Oeffinger,M. (2016) Single-Step Affinity Purification (sSAP) and Mass Spectrometry of Macromolecular Complexes in the Yeast S. cerevisiae. Methods Mol Biol, 1361, 265-287.

37. Tafforeau,L., Zorbas,C., Langhendries,J.-L., Mullineux,S.-T., Stamatopoulou,V., Mullier,R., Wacheul,L. and Lafontaine,D.L.J. (2013) The Complexity of Human Ribosome Biogenesis Revealed by Systematic Nucleolar Screeningof Pre-rRNA Processing Factors. Mol Cell, 51, 539-551.

38. Mellacheruvu,D., Wright,Z., Couzens,A.L., Lambert,J.-P., St-Denis,N.A., Li,T., Miteva,Y.V., Hauri,S., Sardiu,M.E., Low,T.Y., et al. (2013) The CRAPome: a contaminant repository for affinity purificationmass spectrometry data. Nat Meth, 10, 730-736.

39. Thiry,M. and Lafontaine,D.L.J. (2005) Birth of a nucleolus: the evolution of nucleolar compartments. Trends in Cell Biology, 15, 194-199.

40. Passon,D.M., Lee,M., Rackham,O., Stanley,W.A., Sadowska,A., Filipovska,A., Fox,A.H. and Bond,C.S. (2012) Structure of the heterodimer of human NONO and paraspeckle protein component 1 and analysis of its role in subnuclear body formation. Proc Natl Acad Sci USA, 109, 4846-4850.

41. Lee,M., Sadowska,A., Bekere,I., Ho,D., Gully,B.S., Lu,Y., Iyer,K.S., Trewhella,J., Fox,A.H. and Bond,C.S. (2015) The structure of human SFPQ reveals a coiled-coil mediated polymer essential for functional aggregation in gene regulation. Nucleic Acids Res., 43, 3826-3840.

42. Spector,D.L. and Lamond,A.I. (2011) Nuclear Speckles. Cold Spring Harb Perspect Biol, 3, a000646a000646.

43. Decker,C.J. and Parker,R. (2012) P-bodies and stress granules: possible roles in the control of translation and mRNA degradation. Cold Spring Harb Perspect Biol, 4, a012286-a012286.

44. Preti,M., O'Donohue,M.F., Montel-Lehry,N., Bortolin-Cavaille,M.L., Choesmel,V. and Gleizes,P.E. (2013) Gradual processing of the ITS1 from the nucleolus to the cytoplasm during synthesis of the human 18S rRNA. Nucleic Acids Res, 10.1093/nar/gkt160. 
45. MacLaine,N.J. and Hupp,T.R. (2011) How phosphorylation controls p53. Cell Cycle, 10, 916-921.

46. James,A., Wang,Y., Raje,H., Rosby,R. and DiMario,P. (2014) Nucleolar stress with and without p53. nucleus, 5, 402-426.

47. Bunz,F., Dutriaux,A., Lengauer,C., Waldman,T., Zhou,S., Brown,J.P., Sedivy,J.M., Kinzler,K.W. and Vogelstein,B. (1998) Requirement for p53 and p21 to sustain G2 arrest after DNA damage. Science, 282, 1497-1501.

48. Malmlöf,M., Roudier,E., Högberg,J. and Stenius,U. (2007) MEK-ERK-mediated phosphorylation of Mdm2 at Ser-166 in hepatocytes. Mdm2 is activated in response to inhibited Akt signaling. $J$ Biol Chem, 282, 2288-2296.

49. Yan,S., Sorrell,M. and Berman,Z. (2014) Functional interplay between ATM/ATR-mediated DNA damage response and DNA repair pathways in oxidative stress. Cell Mol Life Sci, 71, 3951-3967.

50. Maréchal,A. and Zou,L. (2013) DNA damage sensing by the ATM and ATR kinases. Cold Spring Harb Perspect Biol, 5, a012716-a012716.

51. Jette,N. and Lees-Miller,S.P. (2015) The DNA-dependent protein kinase: A multifunctional protein kinase with roles in DNA double strand break repair and mitosis. Prog. Biophys. Mol. Biol., 117, 194 205.

52. Hickson,I., Zhao,Y., Richardson,C.J., Green,S.J., Martin,N.M.B., Orr,A.I., Reaper,P.M., Jackson,S.P., Curtin,N.J. and Smith,G.C.M. (2004) Identification and characterization of a novel and specific inhibitor of the ataxia-telangiectasia mutated kinase ATM. Cancer Res, 64, 9152-9159.

53. Leahy,J.J.J., Golding,B.T., Griffin,R.J., Hardcastle,I.R., Richardson,C., Rigoreau,L. and Smith,G.C.M. (2004) Identification of a highly potent and selective DNA-dependent protein kinase (DNA-PK) inhibitor (NU7441) by screening of chromenone libraries. Bioorg Med Chem Lett, 14, 6083-6087.

54. Fokas,E., Prevo,R., Pollard,J.R., Reaper,P.M., Charlton,P.A., Cornelissen,B., Vallis,K.A., Hammond,E.M., Olcina,M.M., Gillies McKenna,W., et al. (2012) Targeting ATR in vivo using the novel inhibitor VE-822 results in selective sensitization of pancreatic tumors to radiation. Cell Death Dis, 3, e441.

55. Jobson,A.G., Cardellina,J.H., Scudiero,D., Kondapaka,S., Zhang,H., Kim,H., Shoemaker,R. and Pommier,Y. (2007) Identification of a Bis-guanylhydrazone [4,4'-Diacetyldiphenylureabis(guanylhydrazone); NSC 109555] as a novel chemotype for inhibition of Chk2 kinase. Mol. Pharmacol., 72, 876-884.

56. Tse,A.N., Rendahl,K.G., Sheikh,T., Cheema,H., Aardalen,K., Embry,M., Ma,S., Moler,E.J., Ni,Z.J., Lopes de Menezes,D.E., et al. (2007) CHIR-124, a novel potent inhibitor of Chk1, potentiates the cytotoxicity of topoisomerase I poisons in vitro and in vivo. Clin. Cancer Res., 13, 591-602.

57. Panier,S. and Boulton,S.J. (2014) Double-strand break repair: 53BP1 comes into focus. Nat Rev Mol Cell Biol, 15, 7-18.

58. Block,W.D., Merkle,D., Meek,K. and Lees-Miller,S.P. (2004) Selective inhibition of the DNAdependent protein kinase (DNA-PK) by the radiosensitizing agent caffeine. Nucleic Acids Res, 32 , 1967-1972.

59. Salton,M., Lerenthal,Y., Wang,S.-Y., Chen,D.J. and Shiloh,Y. (2010) Involvement of Matrin 3 and SFPQ/NONO in the DNA damage response. Cell Cycle, 9, 1568-1576. 
60. Li,S., Li,Z., Shu,F.-J., Xiong,H., Phillips,A.C. and Dynan,W.S. (2014) Double-strand break repair deficiency in NONO knockout murine embryonic fibroblasts and compensation by spontaneous upregulation of the PSPC1 paralog. Nucleic Acids Res, 42, 9771-9780.

61. Sloan,K.E., Bohnsack,M.T., Schneider,C. and Watkins,N.J. (2014) The roles of SSU processome components and surveillance factors in the initial processing of human ribosomal RNA. RNA, 10.1261/rna.043471.113.

62. Morello,L.G., Coltri,P.P., Quaresma,A.J.C., Simabuco,F.M., Silva,T.C.L., Singh,G., Nickerson,J.A., Oliveira,C.C., Moore,M.J. and Zanchin,N.I.T. (2011) The human nucleolar protein FTSJ3 associates with NIP7 and functions in pre-rRNA processing. PLoS ONE, 6, e29174.

63. Schillewaert,S., Wacheul,L., Lhomme,F. and Lafontaine,D.L.J. (2011) The Evolutionarily Conserved Protein LAS1 Is Required for Pre-rRNA Processing at Both Ends of ITS2. Mol Cell Biol, 32, 430-444.

64. Marinho,J., Martins,T., Neto,M., Casares,F. and Pereira,P.S. (2013) The nucleolar protein Viriato/Nol12 is required for the growth and differentiation progression activities of the Dpp pathway during Drosophila eye development. Dev. Biol., 377, 154-165.

65. Sylvester,J.E., Fischel-Ghodsian,N., Mougey,E.B. and O'Brien,T.W. (2004) Mitochondrial ribosomal proteins: candidate genes for mitochondrial disease. Genet. Med., 6, 73-80.

66. He,J., Cooper,H.M., Reyes,A., Di Re,M., Sembongi,H., Litwin,T.R., Gao,J., Neuman,K.C., Fearnley,I.M., Spinazzola,A., et al. (2012) Mitochondrial nucleoid interacting proteins support mitochondrial protein synthesis. Nucleic Acids Res, 40, 6109-6121.

67. Rötig,A. (2014) Genetics of mitochondrial respiratory chain deficiencies. Rev. Neurol. (Paris), 170, 309-322.

68. Stelzl,U., Worm,U., Lalowski,M., Haenig,C., Brembeck,F.H., Goehler,H., Stroedicke,M., Zenkner,M., Schoenherr,A., Koeppen,S., et al. (2005) A human protein-protein interaction network: a resource for annotating the proteome. Cell, 122, 957-968.

69. Oláh,J., Vincze,O., Virók,D., Simon,D., Bozsó,Z., Tõkési,N., Horváth,I., Hlavanda,E., Kovács,J., Magyar,A., et al. (2011) Interactions of pathological hallmark proteins: tubulin polymerization promoting protein/p25, beta-amyloid, and alpha-synuclein. J Biol Chem, 286, 34088-34100.

70. Baltz,A.G., Munschauer,M., Schwanhäusser,B., Vasile,A., Murakawa,Y., Schueler,M., Youngs,N., Penfold-Brown,D., Drew,K., Milek,M., et al. (2012) The mRNA-bound proteome and its global occupancy profile on protein-coding transcripts. Mol Cell, 46, 674-690.

71. Castello,A., Fischer,B., Eichelbaum,K., Horos,R., Beckmann,B.M., Strein,C., Davey,N.E., Humphreys,D.T., Preiss, T., Steinmetz,L.M., et al. (2012) Insights into RNA biology from an atlas of mammalian mRNA-binding proteins. Cell, 149, 1393-1406.

72. Osenberg,S., Dominissini,D., Rechavi,G. and Eisenberg,E. (2009) Widespread cleavage of A-to-I hyperediting substrates. RNA, 15, 1632-1639.

73. Gao,X., Zhang,G., Shan,S., Shang,Y., Chi,L., Li,H., Cao,Y., Zhu,X., Zhang,M. and Yang,J. (2016) Depletion of Paraspeckle Protein 1 Enhances Methyl Methanesulfonate-Induced Apoptosis through Mitotic Catastrophe. PLOS ONE, 11, e0146952.

74. Calo,E., Flynn,R.A., Martin,L., Spitale,R.C., Chang,H.Y. and Wysocka,J. (2015) RNA helicase DDX21 coordinates transcription and ribosomal RNA processing. Nature, 518, 249-253. 
75. Geissler,R., Golbik,R.P. and Behrens,S.E. (2012) The DEAD-box helicase DDX3 supports the assembly of functional 80 S ribosomes. Nucleic Acids Res, 10.1093/nar/gks070.

76. Jain,A., Bacolla,A., Del Mundo,I.M., Zhao,J., Wang,G. and Vasquez,K.M. (2013) DHX9 helicase is involved in preventing genomic instability induced by alternatively structured DNA in human cells. Nucleic Acids Res, 41, 10345-10357.

77. Mills,J.R., Malina,A., Lee,T., Di Paola,D., Larsson,O., Miething,C., Grosse,F., Tang,H., ZannisHadjopoulos,M., Lowe,S.W., et al. (2013) RNAi screening uncovers Dhx9 as a modifier of ABT-737 resistance in an E $\mu-\mathrm{myc} / \mathrm{Bcl}-2$ mouse model. Blood, 121, 3402-3412.

78. Herrera-Moyano,E., Mergui,X., García-Rubio,M.L., Barroso,S. and Aguilera,A. (2014) The yeast and human FACT chromatin-reorganizing complexes solve R-loop-mediated transcription-replication conflicts. Genes Dev, 28, 735-748. 
bioRxiv preprint doi: https://doi.org/10.1101/043935; this version posted March 16, 2016. The copyright holder for this preprint (which was not certified by peer review) is the author/funder, who has granted bioRxiv a license to display the preprint in perpetuity. It is made available under aCC-BY-NC-ND 4.0 International license.

\section{FIGURES AND LEGENDS}

Scott,Trahan et al., Figure 1

a
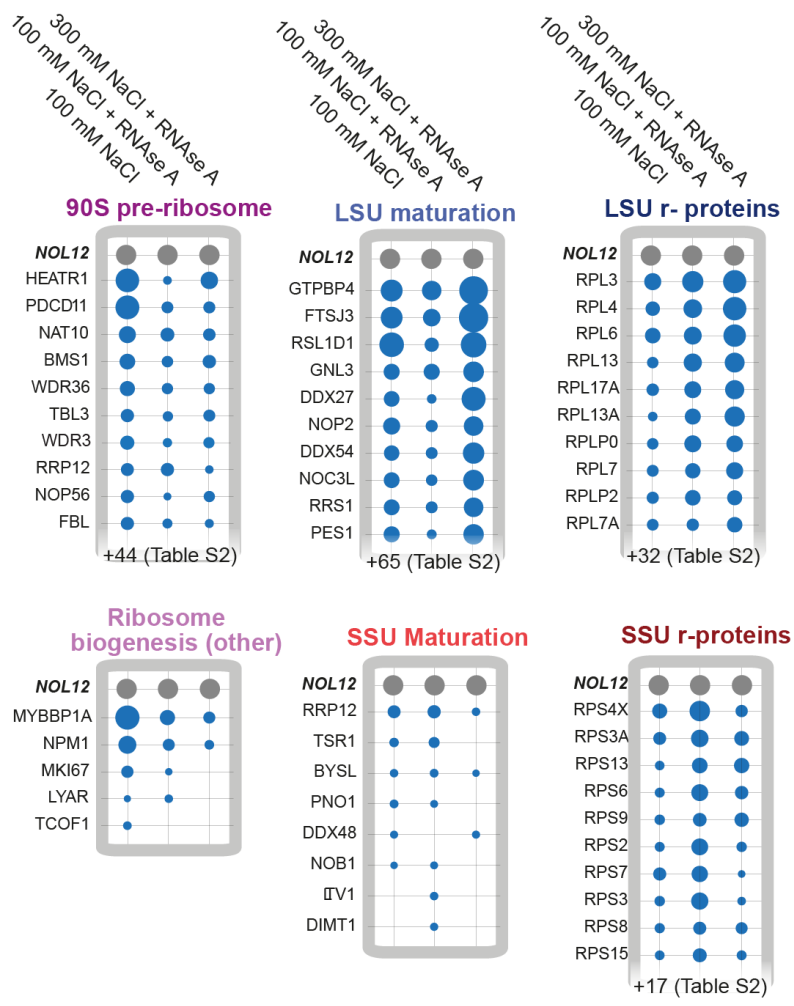

b

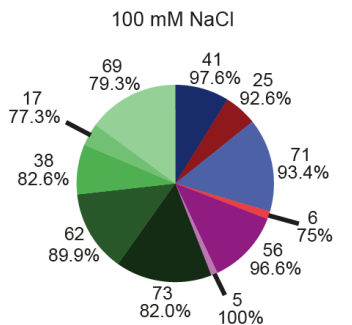

$300 \mathrm{mM} \mathrm{NaCl}+$ RNAse A

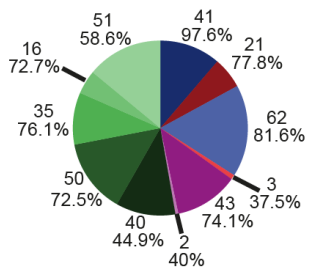

$100 \mathrm{mM} \mathrm{NaCl}+$ RNAse A

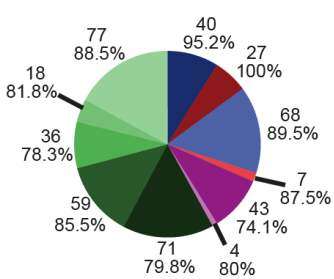

- LSU proteins

- SSU proteins

- LSU maturation

- SSU maturation

90S pre-ribosome

- Ribosome biogenesis (other)

mRNAmetabolism

cytoskeleton

- Mitochondrial proteins

- Chromatin-associated

Miscellaneous

Figure 1. Nol12 associates with a diverse range of complexes. PrA-Nol12-associated complexes were affinity purified from HEK293T cells. Peptides enriched more than 2-fold over negative controls (untagged and PrA-only cell lines) and present in $\geq 3$ peptides in all replicates, were identified and mapped 
to the human proteome. (a) Total unique peptide counts for enriched peptides were normalized against bait peptide counts, and resulting relative peptide counts for each condition were plotted as radii of a circle (10 most-enriched proteins shown here). (b) The numbers of proteins from each functional class (based on GO terms) found associated with PrA-Nol12 under each purification condition were calculated. Percentages represent the relative coverage of proteins from the particular functional class identified under that condition; pie graph sizes are proportional to the total size of the PrA-Nol12 interactome under that condition. 

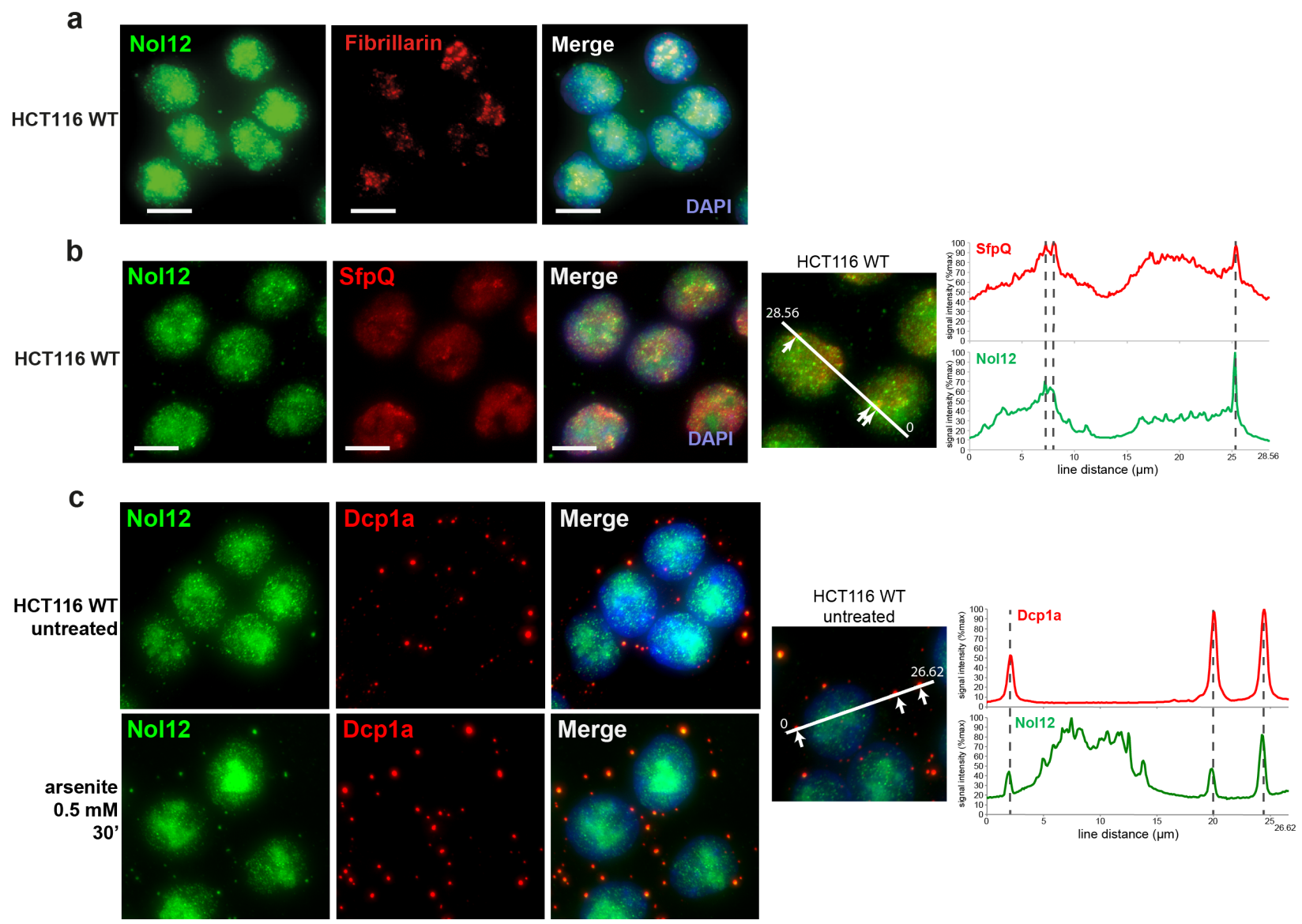

Figure 2: Nol12 co-localizes with nucleoli, paraspeckles, mitochondria and GW/P-bodies.

Endogenous Nol12 localization in HCT116 WT cells was compared to that of the nucleolar marker Fibrillarin (a), the paraspeckle component SfpQ (b), and the GW/P-body component Dcp1a (c). Images are representative of three independent experiments. Scale bar $=10 \mu \mathrm{m}$. For (c) HCT116 WT cells were grown on poly-L-lysine-coated coverslips for $48 \mathrm{~h}$, with or without treatment with sodium arsenite $(0.5 \mathrm{mM}$, 30 ') prior to fixation, imaging and trace analysis. (b, c) Linear profiles of fluorescence density were created from representative images of each co-immunofluorescence experiment and normalized against the maximum observed fluorescence along the line segment. Arrows/dotted lines indicate the location of local fluorescence maxima in the marker channel; colocalization was analysed using the Fiji software Coloc2 module. 
bioRxiv preprint doi: https://doi.org/10.1101/043935; this version posted March 16, 2016. The copyright holder for this preprint (which was not certified by peer review) is the author/funder, who has granted bioRxiv a license to display the preprint in perpetuity. It is made available under aCC-BY-NC-ND 4.0 International license.

\section{Scott, Trahan et al., Figure 3}

a

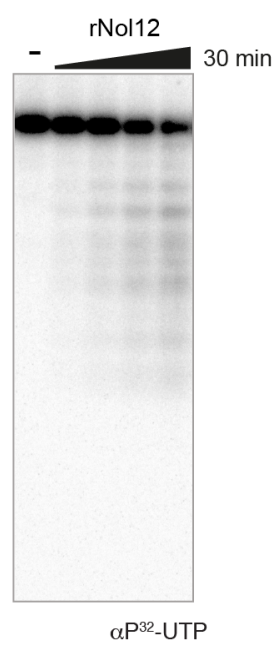

C

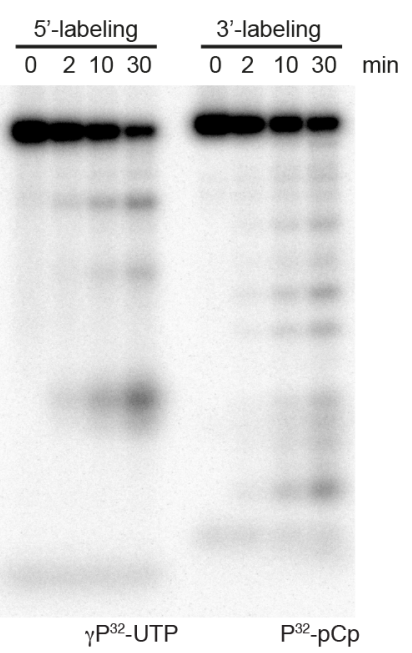

b

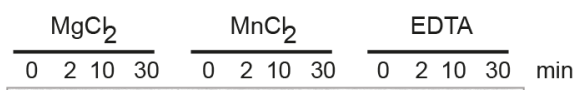

d

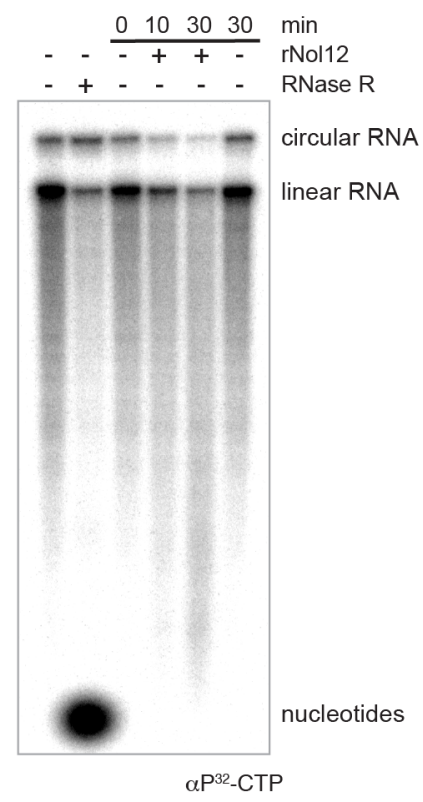

Figure 3. Nol12 is an RNA endonuclease. (a) Nuclease assays using in vitro transcribed radiolabeled RNA ( $\alpha P^{32}$-UTP) and recombinant rNol12. Increasing rNol12 concentrations up to $1.5 \mu \mathrm{M}$ were incubated at $30{ }^{\circ} \mathrm{C}$ for 30 minutes before being resolved on a $12 \%$ denaturing acrylamide gel. (b) Recombinant 
Nol12 was incubated with in vitro transcribed radiolabeled RNA ( $\left.\alpha \mathrm{P}^{32}-\mathrm{UTP}\right)$ at $30{ }^{\circ} \mathrm{C}$ for $0,2,10$ and 30 minutes in the presence of $\mathrm{MgCl}_{2}, \mathrm{MnCl}_{2}$ or excess EDTA before being resolved on a $12 \%$ denaturing acrylamide gel. Images are representative of three independent experiments. (c) Degradation of in vitro transcribed 5'- $\gamma \mathrm{P}^{32}$-ATP (left) or 3'- $\mathrm{pCp}-\alpha \mathrm{P}^{32}$ (right) end-labeled ssRNA by rNol12. (d) Nuclease assay performed on a mixture of linear and circular RNA. RNA alone (lane 1) was treated with RNase R (lane 2) exonuclease. The RNA was incubated in nuclease buffer without rNol12 for 0 and 30 min (lanes 3, 6), and with rNol12 for 10 and 30 minutes (lanes 4-5). 
a
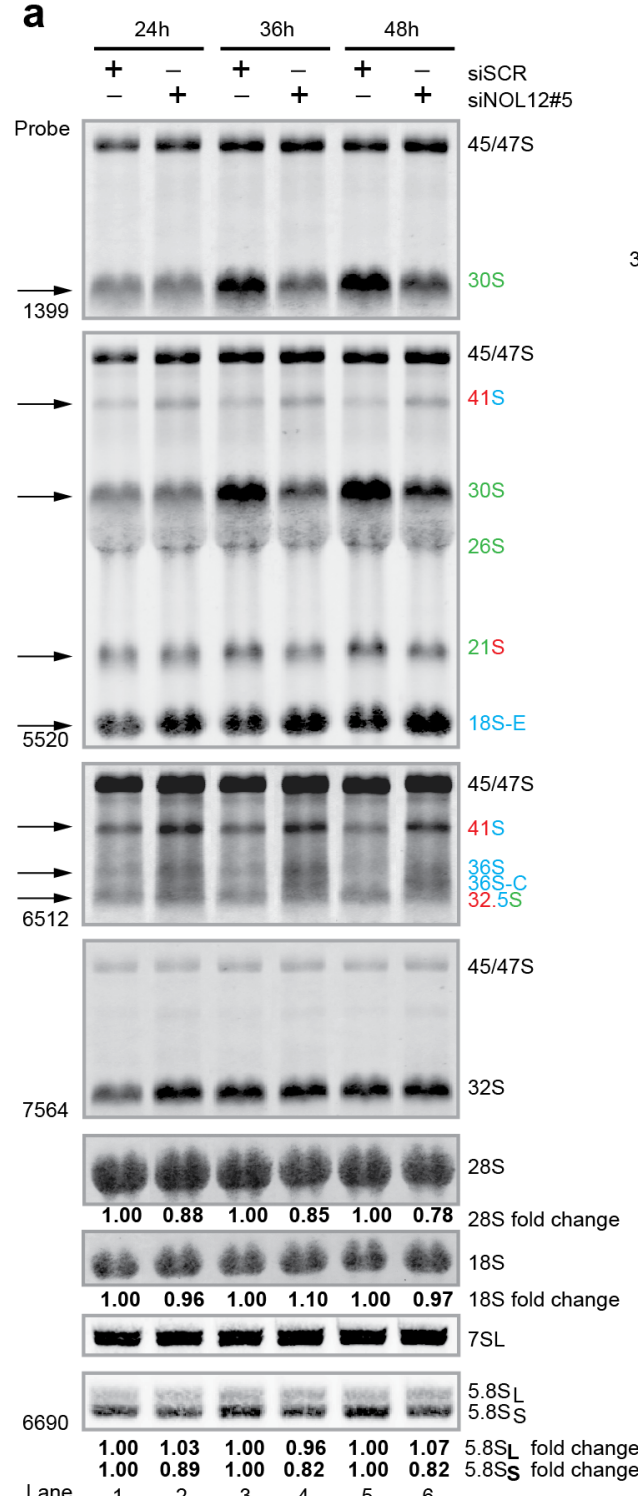

b

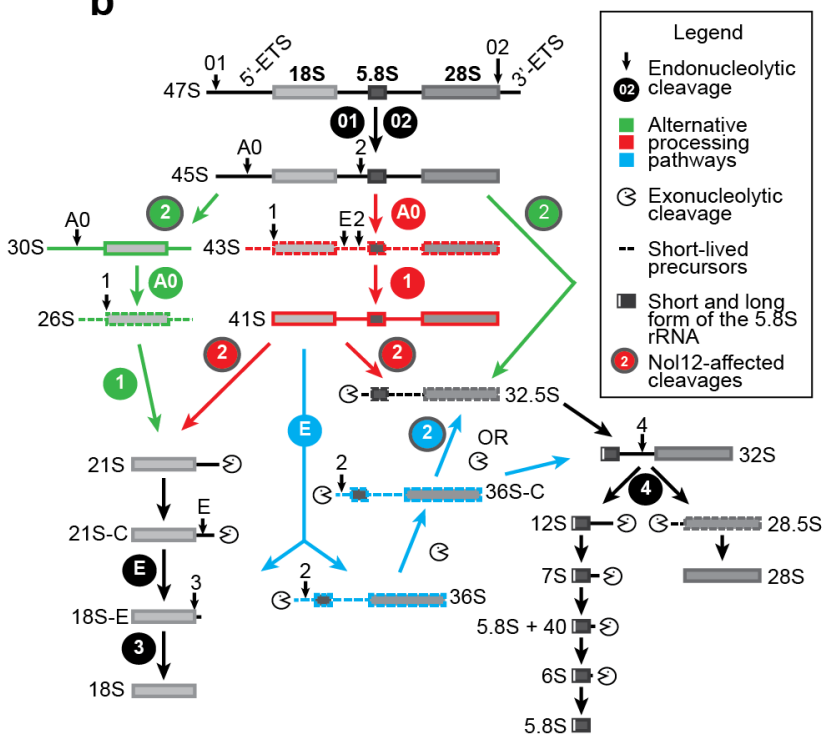

C

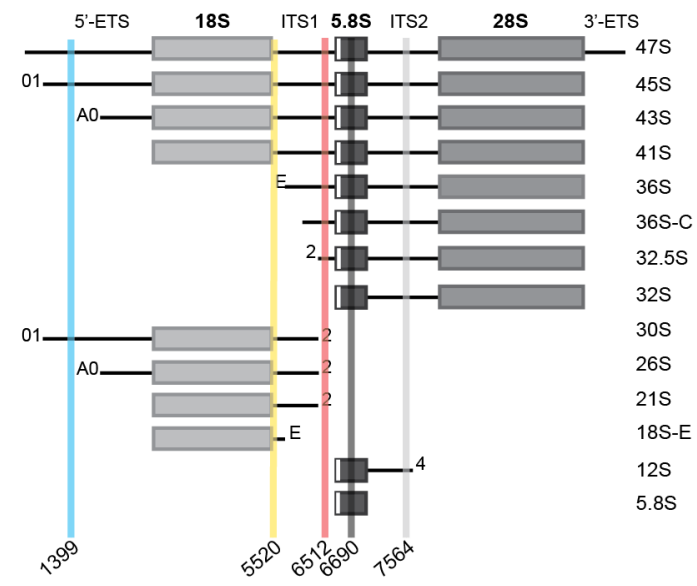

Figure 4. Nol12 is required for large and small ribosomal subunit maturation. (a) Total RNA extracted at different time points from HCT116 WT cells transfected with siNOL12\#5 or siSCR was analyzed by Northern blotting using probes hybridizing to either 5'-ETS, ITS1 or ITS2 regions of the prerRNA to detect processing intermediates. RNA loading was monitored by methylene blue staining of 
bioRxiv preprint doi: https://doi org/101101/043935; this version posted March 16, 2016. The copyright holder for this preprint (which was not certified by peer review) is the author/funder, who has granted bioRxiv a license to display the preprint in perpetuity. It is made available under aCC-BY-NC-ND 4.0 International license.

mature $18 \mathrm{~S}$ and $28 \mathrm{~S}$ rRNAs (large RNAs) or Northern blotting for the 7SL RNA (small RNAs). A schematic of rRNA maturation pathways in human cells is shown in (b), and the relative positions of probes used with respect to different rRNA processing intermediates are shown in (c). 
bioRxiv preprint doi: https://doi org/10.1101/043935; this version posted March 16, 2016. The copyright holder for this preprint (which was not certified by peer review) is the author/funder, who has granted bioRxiv a license to display the preprint in perpetuity. It is made available under aCC-BY-NC-ND 4.0 International license.

a

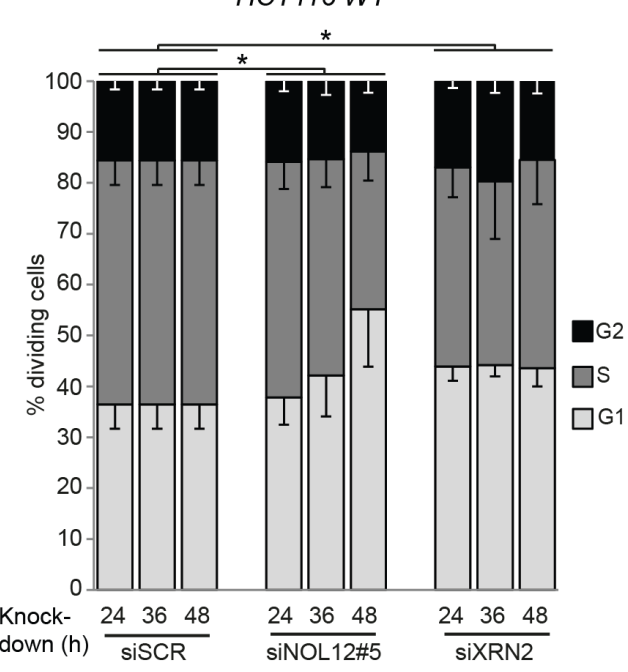

d

f

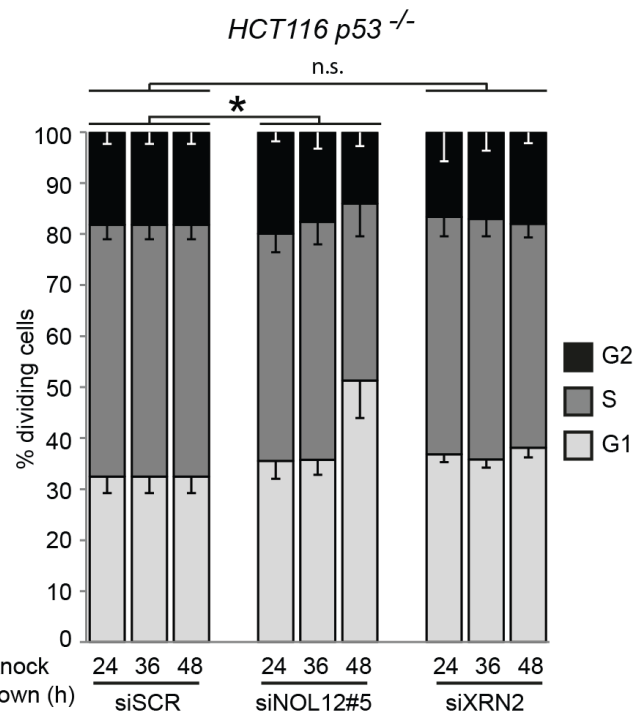

b

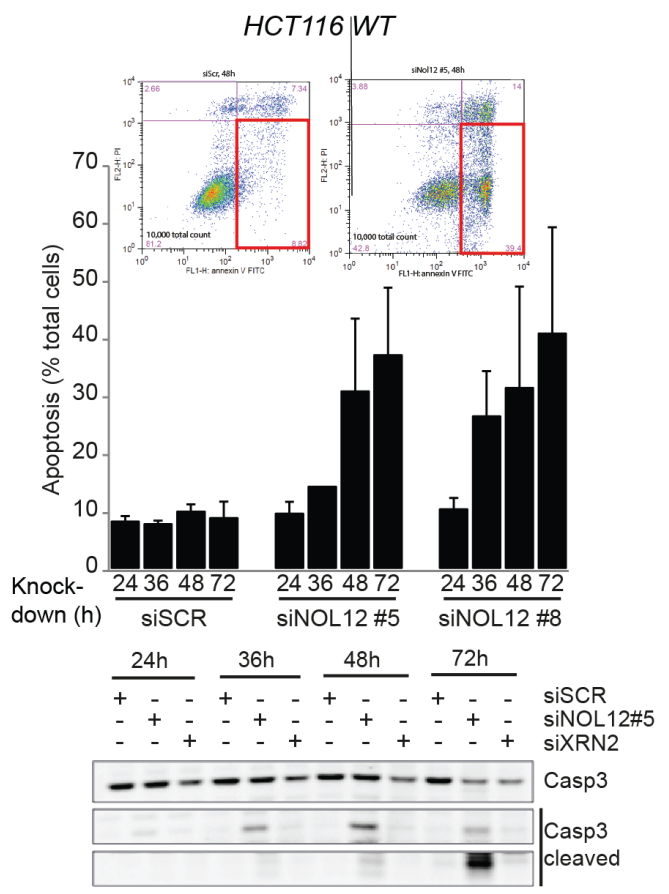

e

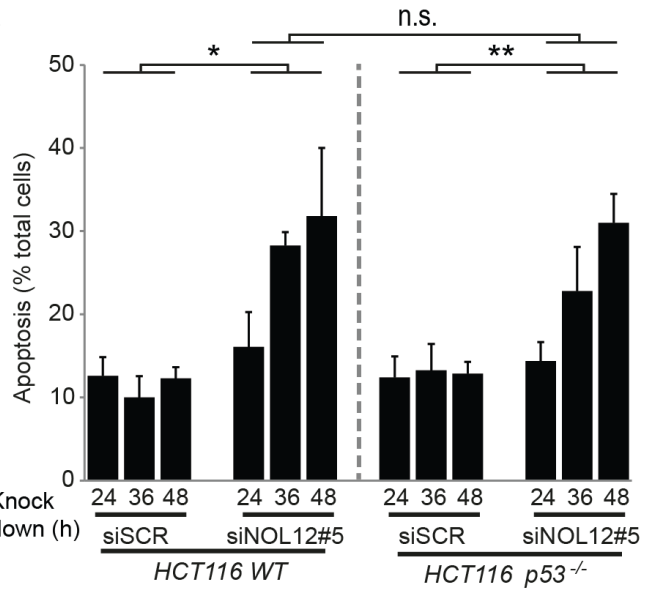

g

HCT116 p53 - -

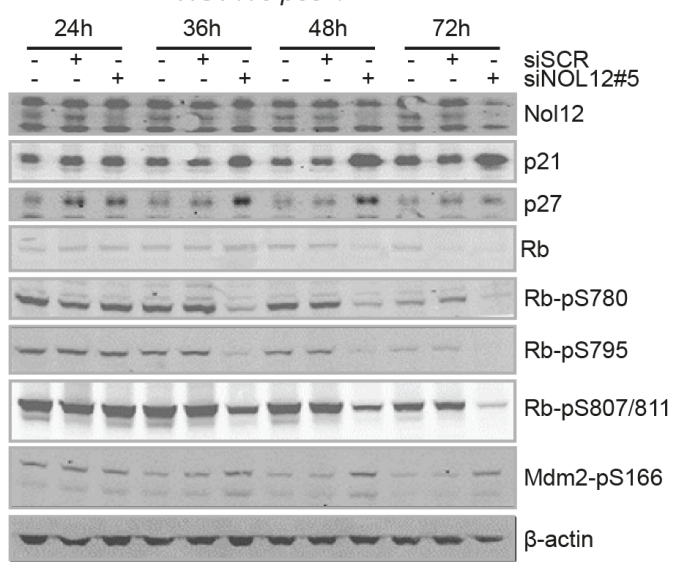


Figure 5. NOL12 knockdown causes p53-independent $\mathbf{G}_{1} / \mathbf{S}$ arrest and apoptosis. (a-d) HCT116 WT cells were transfected with the indicated siRNAs $(10 \mu \mathrm{M})$ for the times specified. (a) Propidium lodide (PI)stained DNA content was quantified by FACS, and $G_{1}(2 n), S(2 n-4 n)$ and $G_{2}(4 n)$ populations determined. Data represent mean \pm s.d. for five independent experiments. ${ }^{*} p<0.05$ by Student's two-tailed $t$-test on area under the curve (AUC) of $\mathrm{G}_{1}$ or $\mathrm{AV}^{+} \mathrm{PI}^{-}$populations as appropriate. (b) Annexin V-FITCpositive, PI-negative apoptotic cells (gated, inset) were quantified by FACS. Data represents mean \pm s.d. for two independent experiments. (c, d) Whole cell extracts (WCEs) of siRNA-treated cells were resolved on $4-12 \%$ Bis-Tris gradient gels, transferred to PVDF membrane and blotted with the indicated primary antibodies. (e-g) HCT116 $p 53^{-/-}$cells were treated with the indicated siRNAs $(10 \mu \mathrm{M})$ for the specified times. (e) HCT 116 WT or $p 53^{-/}$cells were treated with siSCR or siNOL12\#5 $(10 \mu \mathrm{M})$ for the times indicated, and apoptotic cells quantified. Annexin V-FITC-positive, PI-negative apoptotic cells (gated, inset) were quantified by FACS. Data represents mean \pm s.d. for two independent experiments. * $p<0.05$, ** $p<0.05$, n.s., non-significant by Student's two-tailed $t$-test on area under the curve (AUC) of $G_{1}$ or $A V^{+}$ $\mathrm{PI}^{-}$populations as appropriate. (f) Propidium lodide (PI)-stained DNA content was quantified by FACS, and $G_{1}(2 n), S(2 n-4 n)$ and $G_{2}(4 n)$ populations determined. Data represent mean \pm s.d. for five independent experiments. (g) HCT116 $p 53^{-/-}$cells were treated with the indicated siRNAs $(10 \mu \mathrm{M})$ for the specified times. Whole cell extracts (WCEs) of siRNA-treated cells were resolved on $4-12 \%$ Bis-Tris gradient gels, transferred to PVDF membrane and blotted with the indicated primary antibodies. 
bioRxiv preprint doi: https://doi org/10.1101/043935; this version posted March 16, 2016. The copyright holder for this preprint (which was not

a

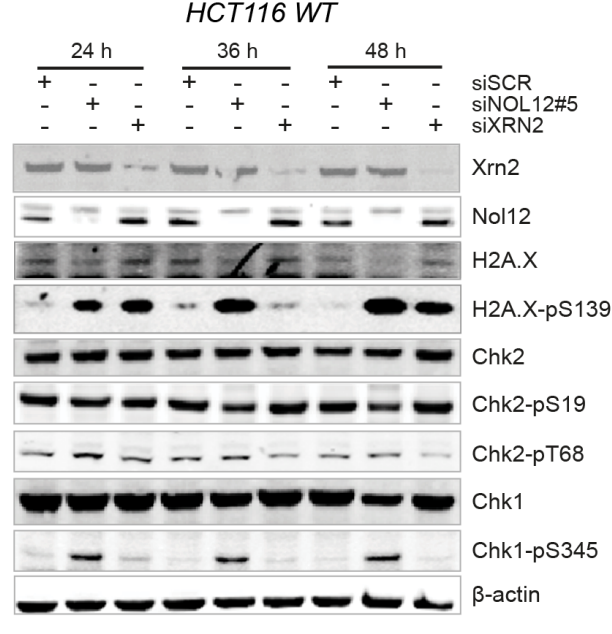

C

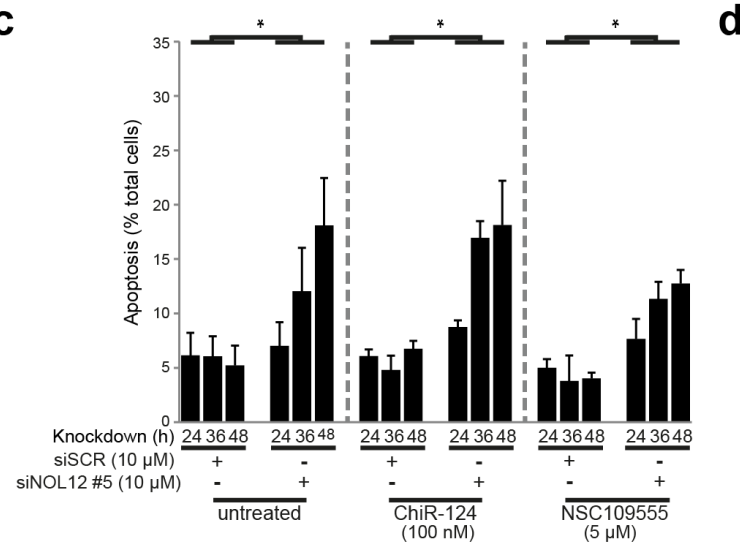

b

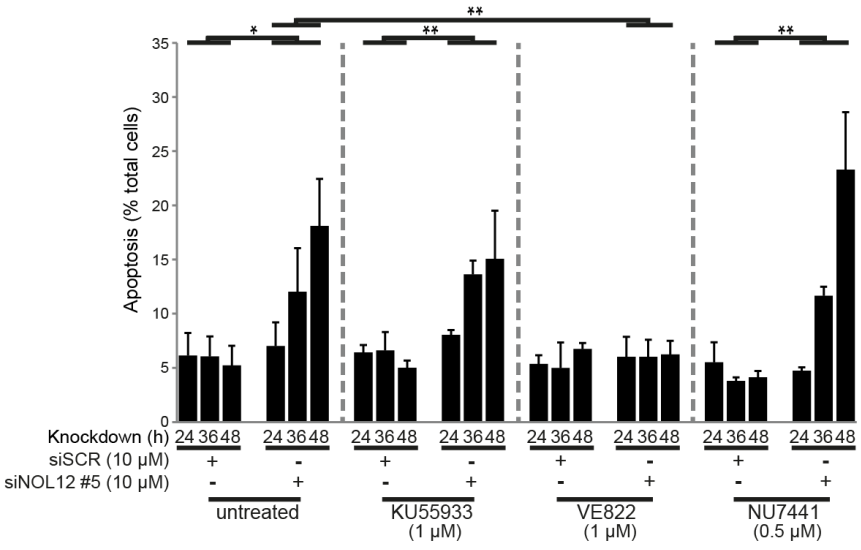

d

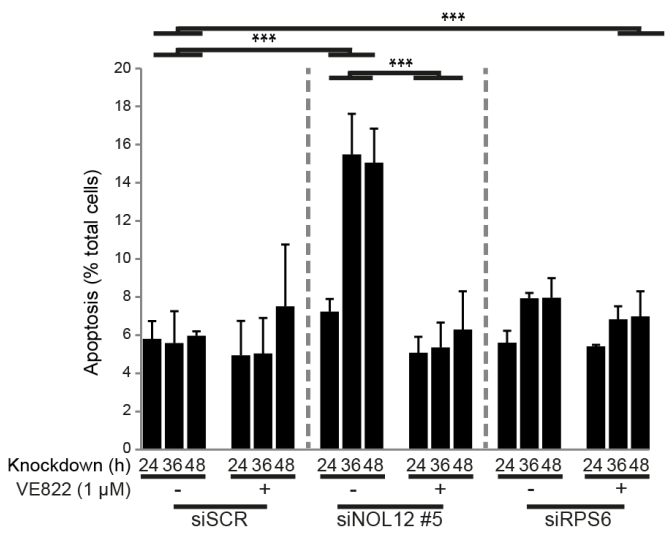

e
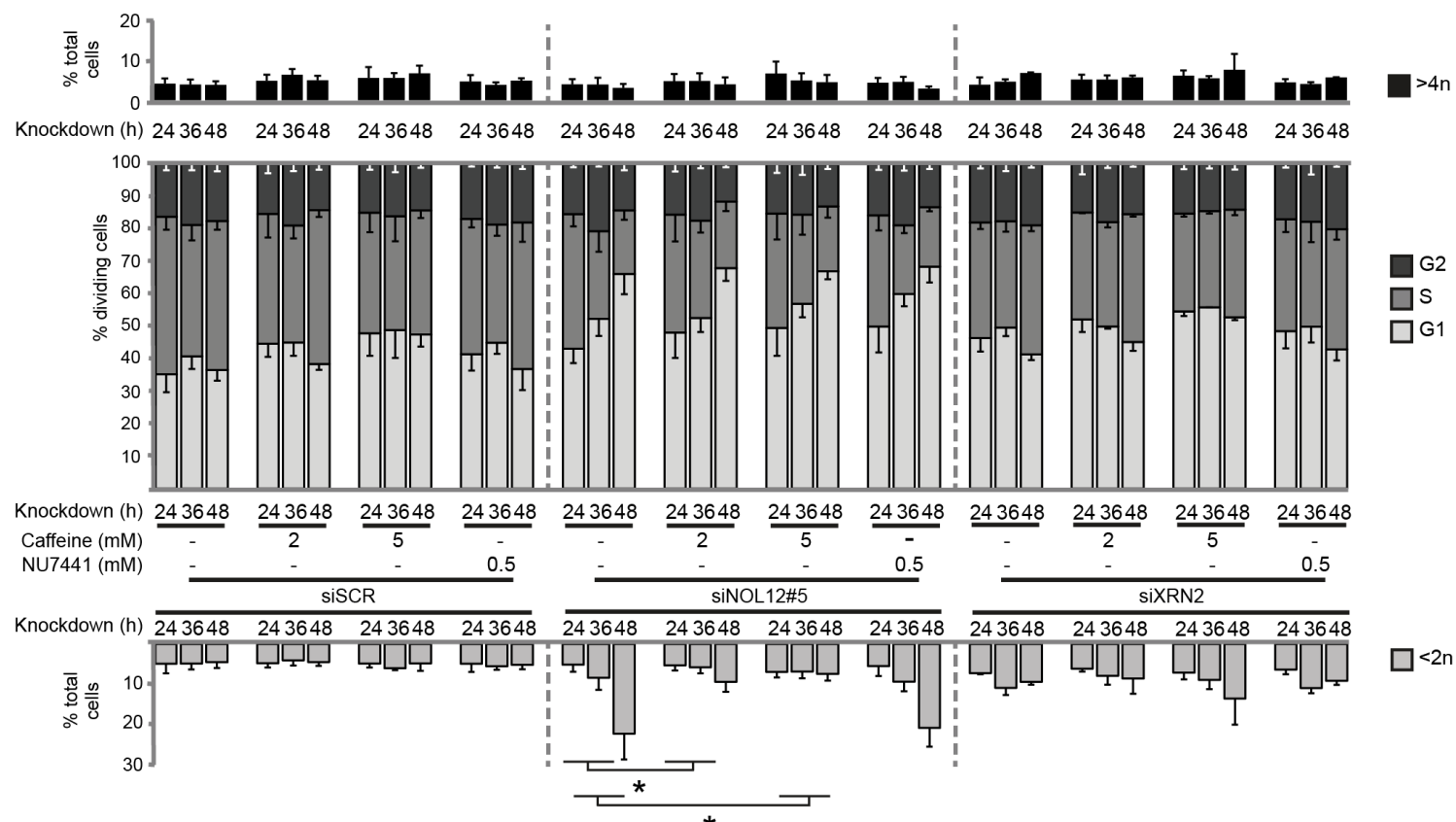
Figure 6. Loss of Nol12 causes apoptosis via ATR signaling. (a) WCEs of HCT116 WT cells treated with indicated siRNAs for the times specified were resolved on $4-12 \%$ Bis-Tris gradient gels, transferred to PVDF membrane and blotted with the indicated primary antibodies. (b) HCT116 WT cells were transfected with siSCR or siNOL12\#5 $(10 \mu \mathrm{M})$ as indicated and grown in the presence of KU55933 $(1 \mu \mathrm{M}$;

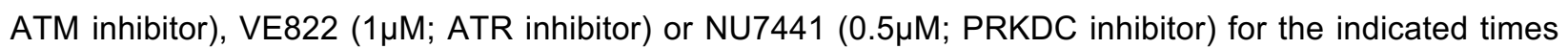
prior to quantification of apoptotic cells by FACS as in Figure 5b. Data represents mean \pm s.d. for four

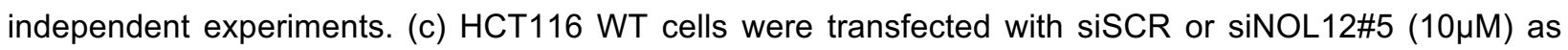

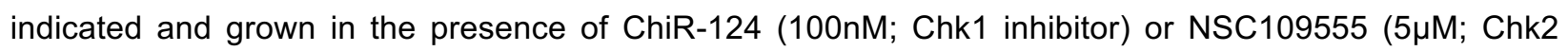
inhibitor) for the indicated times prior to quantification of apoptotic cells as in Figure 4B. Data represents mean \pm s.d. for four independent experiments. (d) HCT116 WT cells treated with the indicated siRNAs and grown in the presence or absence of VE822 $(1 \mu \mathrm{M})$ for the indicated times prior to quantification of apoptotic cells as in (b). Data represents mean \pm s.d. for four independent experiments. (e) HCT116 WT cells treated with the indicated siRNAs were grown in the presence of caffeine (2 or 5mM) or NU7441 $(0.5 \mu \mathrm{M})$ for the indicated times prior to analysis as described in Figure $4 \mathrm{~A}$ except that $<2 \mathrm{n}$ and $>4 \mathrm{n}$ populations were also scored. Data represents mean \pm s.d. for $>4$ independent experiments. * $p<0.05,{ }^{* *}$ $\mathrm{p}<0.01,{ }^{* *} \mathrm{p}<0.005$ by Student's two-tailed $t$-test on $\mathrm{AUCs}$ of $\mathrm{AV}^{+} \mathrm{PI}^{-}$or $<2 \mathrm{n}$ populations as appropriate. 
bioRxiv preprint doi: https://doi.org/10.1101/043935; this version posted March 16, 2016. The copyright holder for this preprint (which was not certified by peer review) is the author/funder, who has granted bioRxiv a license to display the preprint in perpetuity. It is made available under aCC-BY-NC-ND 4.0 International license.

Scott, Trahan et al., Figure 7
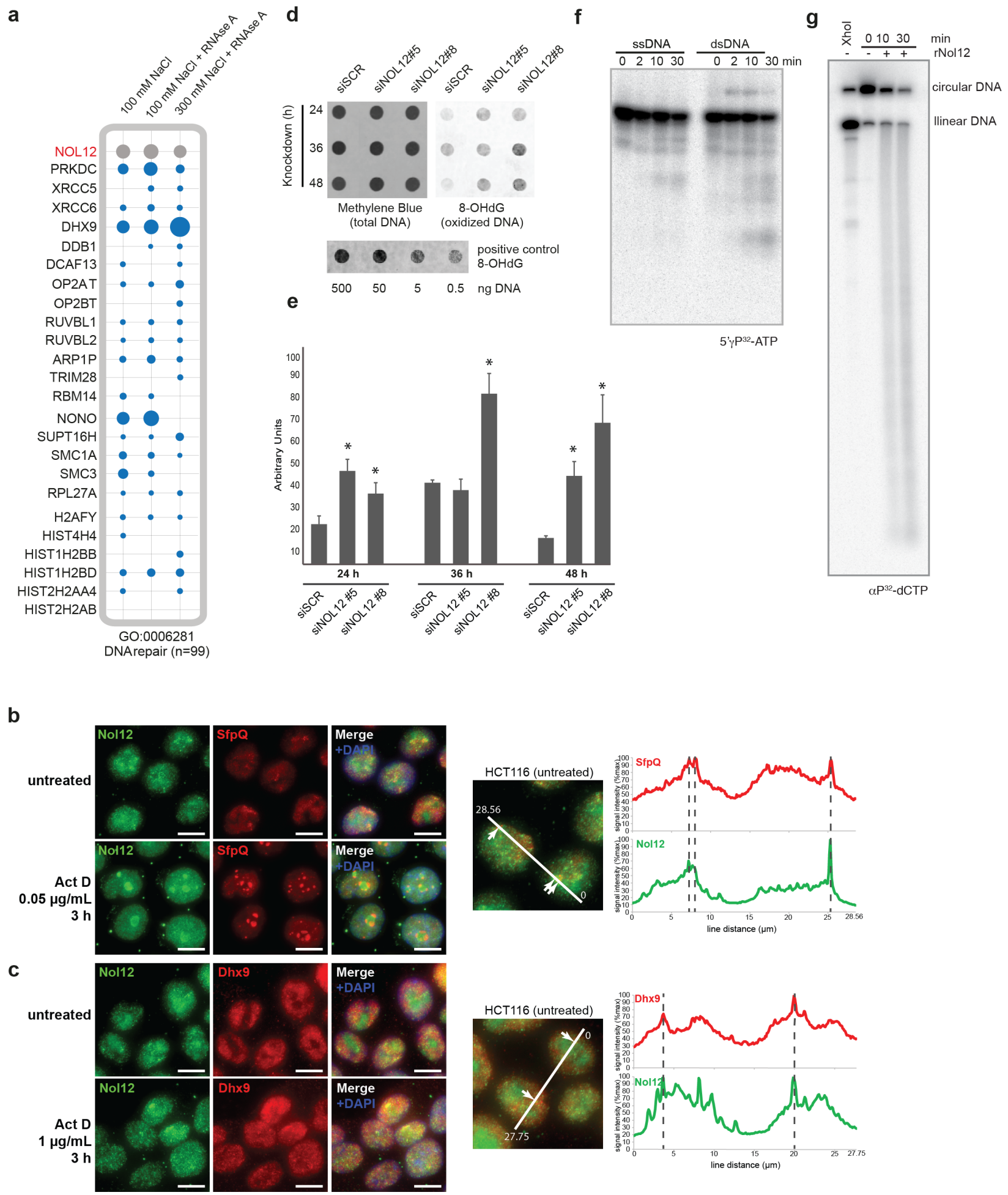
Figure 7. Nol12 associates with DDR factors and is required for suppression of oxidative DNA damage. (a) PrA-Nol12 associated proteins identified by MS analysis with a "DNA repair" gene ontology annotation (GO:0006281). Dots represent semi-quantitative analyses. (b, c) Endogenous Nol12 localization in HCT116 WT cells was compared to that of the paraspeckle component SfpQ (b, red) and to that of the RNA/DNA DEAD-box helicase Dhx9 (c-red; arrows) in untreated and actinomycin D-treated cells. Images are representative of three independent experiments. Scale bar $=10 \mu \mathrm{m}$. In each case HCT116 WT cells were grown on poly-L-lysine-coated coverslips for 48h, with or without treatment actinomycin $\mathrm{D}$ (either $0.05 \mu \mathrm{g} / \mathrm{ml}$ (b) or $1 \mu \mathrm{g} / \mathrm{ml}$ (c), 3h) prior to fixation, imaging and trace analysis. Linear profiles of fluorescence density were created from representative images of each co-immunofluorescence experiment and normalized against the maximum observed fluorescence along the line segment. Arrows/dotted lines indicate the location of local fluorescence maxima in the marker channel, and colocalization was analysed using the Fiji software Coloc2 module. (d) DNA purified from HCT WT cells, siRNA-treated as indicated, was spotted onto a nylon membrane. Oxidized DNA was detected using an anti-8-OHdG antibody, and (e) quantified densitometrically. Data represent mean \pm s.d. for three independent experiments; * $\mathrm{p}<0.05$ vs. siSCR treatment by Student's two-tailed $t$-test. (f) In vitro 5'radiolabeled ssDNA, dsDNA $\left(\gamma \mathrm{P}^{32}-\mathrm{ATP}\right)$ or $(\mathrm{g})$ circular dsDNA $\left(\alpha \mathrm{P}^{32}-\mathrm{dCTP}\right)$ was incubated for the indicated times with $\mathrm{rNol} 12$ and resolved by denaturing polyacrylamide electrophoresis. Images are representative of three independent experiments. 